\title{
Path Planning for Autonomous Mobile Robots: A Review
}

\author{
José Ricardo Sánchez-Ibáñez *(D), Carlos J. Pérez-del-Pulgar (i) and Alfonso García-Cerezo (i)
}

Space Robotics Laboratory, Department of Systems Engineering and Automation, Universidad de Málaga, C/Ortiz Ramos s/n, 29071 Málaga, Spain; carlosperez@uma.es (C.J.P.-d.-P.); ajgarcia@uma.es (A.G.-C.)

* Correspondence: ricardosan@uma.es; Tel.: +34-951952527

Citation: Sánchez-Ibáñez, J.R.; Pérez-del-Pulgar, C.J.; García-Cerezo, A. Path Planning for Autonomous Mobile Robots: A Review. Sensors 2021, 21, 7898. https://doi.org/10.3390/s21237898

Academic Editor: Saso Blazic

Received: 16 October 2021

Accepted: 23 November 2021

Published: 26 November 2021

Publisher's Note: MDPI stays neutral with regard to jurisdictional claims in published maps and institutional affiliations.

Copyright: (c) 2021 by the authors. Licensee MDPI, Basel, Switzerland. This article is an open access article distributed under the terms and conditions of the Creative Commons Attribution (CC BY) license (https:// creativecommons.org/licenses/by/ $4.0 /)$.

\begin{abstract}
Providing mobile robots with autonomous capabilities is advantageous. It allows one to dispense with the intervention of human operators, which may prove beneficial in economic and safety terms. Autonomy requires, in most cases, the use of path planners that enable the robot to deliberate about how to move from its location at one moment to another. Looking for the most appropriate path planning algorithm according to the requirements imposed by users can be challenging, given the overwhelming number of approaches that exist in the literature. Moreover, the past review works analyzed here cover only some of these approaches, missing important ones. For this reason, our paper aims to serve as a starting point for a clear and comprehensive overview of the research to date. It introduces a global classification of path planning algorithms, with a focus on those approaches used along with autonomous ground vehicles, but is also extendable to other robots moving on surfaces, such as autonomous boats. Moreover, the models used to represent the environment, together with the robot mobility and dynamics, are also addressed from the perspective of path planning. Each of the path planning categories presented in the classification is disclosed and analyzed, and a discussion about their applicability is added at the end.
\end{abstract}

Keywords: guidance; autonomy; vehicle; survey; trajectory; route; graph search; sampling; wheeled

\section{Introduction}

Autonomous navigation is a valuable asset for mobile robots. It helps to mitigate their dependency on human intervention. However, it also entails many tasks or problems to solve, e.g., path planning. This task lies in finding the best course of action to make a robot reach the desired state from its current one. For example, both states could be, respectively, the goal and the initial position. This course of action comes in the form of a path, also named a route in many other works. The path serves to guide the robot to the desired state in question. However, there may be numerous possible paths, given the free space in which the robot can move. Path planning algorithms generally try to obtain the best path or at least an admissible approximation to it. The best path here refers to the optimal one, in the sense that the resulting path comes from minimizing one or more objective optimization functions. For instance, this path may be the one entailing the least amount of time. This is critical in missions such as those of the search-and-rescue field [1]: victims of a disaster may ask for help in life-or-death situations. Another optimization function to consider could be the energy of the robot. In the case of planetary exploration, this is critical since rovers have limited energetic resources available [2]. At the same time, the path generated by the planner must follow any imposed restrictions. These may come from the limitations in the adaptability of the robot to certain terrains. The locomotion of the robot and the characteristics of the existing terrain limit the kind of manoeuvres that can be performed. This consequently reduces the number of feasible paths that the path planner can generate.

In the literature there are a vast number of path planning approaches and this number has continued to increase over the years. For this reason, selecting the most appropriate approach given certain requirements (for instance, the aforementioned locomotion restrictions) can be a challenging task. Moreover, as discussed below, the latest reviews 
and surveys on path planning do not offer a comprehensive overview of the majority of existing path planning solutions. This is the main motivation for writing this review paper: it describes in detail different path planning categories and, for each of them, introduces relevant representative references found in the literature, focusing on those algorithms aimed at robots that move on top of surfaces (ground, water, etc.). This paper is organized as follows. Section 2 presents the method proposed in this paper to classify the existing path planning algorithms. It also makes clear, following this method, the fact that previous works have important omissions. Moreover, this section also provides an analysis of the methods used to address the environment and locomotion information. The next sections each deal with one of the categories of this classification: Reactive Computing (Section 3), Soft Computing (Section 4), C-Space Search (Section 5) and Optimal Control (Section 6). Finally, Section 7 summarizes the contents of this paper and presents a discussion about the path planning algorithms contained in the aforementioned categories.

\section{Path Planning Algorithms}

Figure 1 depicts the four mentioned categories of path planning, splitting each of them into two subcategories. This classification rests on the principles and fundamental mechanisms used to construct and return a path. A more detailed insight into these categories and why this classification is arranged in this way is provided in the next subsection. A second subsection presents the different approaches taken in modelling the environment and the robot-terrain interaction. We considered it necessary to add this as for many algorithms, especially those in the C-Space Search category, it is necessary to construct these models beforehand.

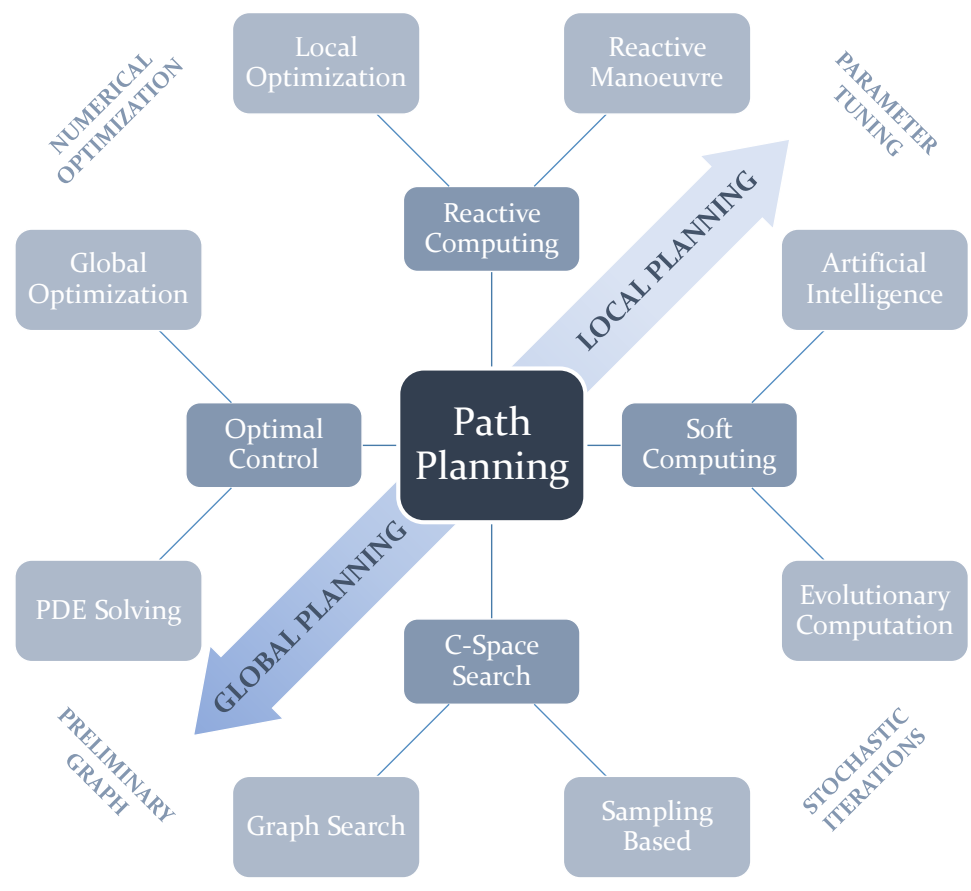

Figure 1. Schematic showing the proposed classification of existing path planning approaches. There are four main categories, each of them containing two subcategories. Two adjacent subcategories from different categories have features in common. The schematic also indicates how some subcategories are more inclined towards either Global Planning or Local Planning.

\subsection{General Classification}

The proposed classification considers how path planning algorithms function. In many past reviews, two kinds of distinction were made: according to whether the environment is dynamic or not; Online and Offline path planners. respectively [3]; and the size of the environment, whether Local or Global. Usually, Online is associated with Local and Offline with Global. The main issue with this is that there are algorithms that can be considered in 
both categories. An algorithm with no replanning capabilities could be used online due to its high computational speed. The contrary could also happen. For instance, a Reactive Computing algorithm called the Dynamic Window Approach (DWA), is usually used for local planning [4], but can also be used for global planning [5]. Vagale et al. [6] presents an interesting division between algorithms that require a preliminary map representation (Classic) [7] and those which do not (Advanced). Classic includes Graph Search methods, whereas Advanced addresses Soft Computing and Sampling-Based algorithms. Souissi et al. [7] proposes several clear and reasonable path planning classifications: according to the robot model (holonomic, non-holonomic, kinodynamic); according to the map model requirement (needed or not needed beforehand); according to the replanning capability (offline or online); and according to whether the algorithm always calculates the same solution or not, according to preliminary configuration parameters (deterministic or probabilistic).

The main purpose of the classification proposed in this paper, depicted in Figure 1, is two-fold. First, this classification aims to encompass a larger variety of algorithms than those that are tackled in past reviews. Many past reviews propose or claim to present a general overview on path planning, but as can be seen in Table 1 the majority of them suffer from important omissions. In this table, Yes means there is significant discussion about the algorithms in question. Only Mentions means the publication acknowledges the existence of at least one or more algorithms in that class. If there are one or two algorithms between parentheses, this means those are only mentioned/referred to briefly. Second, the nomenclature to refer to path planning categories is not clear in some cases. For instance, some other reviews make a distinction between Classical and Heuristic approaches [8,9]. Patle et al. [10] refer to the latter as Reactive. However, the term Classical can be quite an ambiguous term as the majority of planning algorithms used are based on methods with one or more decades of life. This class is also used to encompass many algorithms with completely different ways of functioning. The term Heuristic has not only been used to refer to Evolutionary and Artificial Intelligence algorithms [8], but it has also been also used to refer to Graph Search-based planners [4]. With this in mind, we propose the use of a general classification using four classes (see Figure 1): Reactive Computing, Soft Computing, C-Space Search, and Optimal Control. Moreover, Figure 1 shows how in general terms each of these categories tend to be used mostly for either Local or Global planning. Moreover, each of the subcategories can also have something in common in their functioning with subcategories from other categories, such as the use of numerical methods, the existence of parameters to tune the algorithm beforehand, the requirement of modelling the map with a graph or the use of stochastic iterative processes.

Table 1. Main surveys and reviews of global path planning algorithms found in the literature.

\begin{tabular}{|c|c|c|c|c|c|c|c|c|}
\hline \multirow[b]{2}{*}{ Publication } & \multicolumn{2}{|c|}{ Reactive Computing } & \multicolumn{2}{|c|}{ Soft Computing } & \multicolumn{2}{|c|}{ C-Space Search } & \multicolumn{2}{|c|}{ Optimal Control } \\
\hline & $\begin{array}{c}\text { Reactive } \\
\text { Manoeuvre }\end{array}$ & $\begin{array}{c}\text { Local } \\
\text { Optimization }\end{array}$ & $\begin{array}{l}\text { Evolutionary } \\
\text { Computation }\end{array}$ & $\begin{array}{c}\text { Artificial } \\
\text { Intelligence }\end{array}$ & $\begin{array}{l}\text { Sampling } \\
\text { Based }\end{array}$ & Graph Search & $\begin{array}{l}\text { PDE } \\
\text { Solving }\end{array}$ & $\begin{array}{c}\text { Global } \\
\text { Optimization }\end{array}$ \\
\hline $\begin{array}{l}\text { Raja and Pugazhenthi [3] } \\
\text { (2012) }\end{array}$ & Yes & No & Yes & No & No & No & No & No \\
\hline $\begin{array}{l}\text { Nash and Koenig [11] } \\
\text { (2013) }\end{array}$ & No & No & No & No & $\begin{array}{l}\text { Yes } \\
\text { (RRT and } \\
\text { PRM) }\end{array}$ & $\begin{array}{c}\text { Yes } \\
\text { (Any-angle } \\
\left.\text { and } A^{*}\right)\end{array}$ & No & No \\
\hline $\begin{array}{l}\text { Souissi et al. [7] } \\
\text { (2013) }\end{array}$ & $\begin{array}{c}\text { Yes } \\
\text { (APF) }\end{array}$ & No & $\begin{array}{c}\text { Only } \\
\text { mentions }\end{array}$ & No & Yes & Yes & No & No \\
\hline $\begin{array}{l}\text { Elbanhawi and Simic [12] } \\
\text { (2014) }\end{array}$ & $\begin{array}{c}\text { Only } \\
\text { mentions }\end{array}$ & No & $\begin{array}{c}\text { Only } \\
\text { mentions }\end{array}$ & $\begin{array}{l}\text { Only } \\
\text { mentions }\end{array}$ & Yes & $\begin{array}{c}\text { Only } \\
\text { mentions }\end{array}$ & No & No \\
\hline $\begin{array}{l}\text { González et al. [13] } \\
\text { (2015) }\end{array}$ & No & Yes & No & No & Yes & Yes & No & $\begin{array}{l}\text { Yes } \\
(\mathrm{NLP})\end{array}$ \\
\hline $\begin{array}{l}\text { Mac et al. [8] } \\
\text { (2016) }\end{array}$ & Yes & No & Yes & Yes & Yes & No & No & No \\
\hline $\begin{array}{l}\text { Noreen et al. [14] } \\
\text { (2016) }\end{array}$ & No & No & $\begin{array}{c}\text { Only } \\
\text { mentions }\end{array}$ & No & Yes & $\begin{array}{c}\text { Only } \\
\text { mentions }\end{array}$ & No & No \\
\hline $\begin{array}{l}\text { Injarapu and Gawre [15] } \\
\text { (2017) }\end{array}$ & No & No & $\begin{array}{l}\text { Yes } \\
(\mathrm{GA})\end{array}$ & Yes & No & No & No & No \\
\hline
\end{tabular}


Table 1. Cont.

\begin{tabular}{|c|c|c|c|c|c|c|c|c|}
\hline \multirow[b]{2}{*}{ Publication } & \multicolumn{2}{|c|}{ Reactive Computing } & \multicolumn{2}{|c|}{ Soft Computing } & \multicolumn{2}{|c|}{ C-Space Search } & \multicolumn{2}{|c|}{ Optimal Control } \\
\hline & $\begin{array}{c}\text { Reactive } \\
\text { Manoeuvre }\end{array}$ & $\begin{array}{c}\text { Local } \\
\text { Optimization }\end{array}$ & $\begin{array}{l}\text { Evolutionary } \\
\text { Computation }\end{array}$ & $\begin{array}{c}\text { Artificial } \\
\text { Intelligence }\end{array}$ & $\begin{array}{c}\text { Sampling } \\
\text { Based }\end{array}$ & Graph Search & $\begin{array}{l}\text { PDE } \\
\text { Solving }\end{array}$ & $\begin{array}{c}\text { Global } \\
\text { Optimization }\end{array}$ \\
\hline $\begin{array}{l}\text { Ravankar et al. [16] } \\
\text { (2018) }\end{array}$ & No & Yes & No & No & No & No & No & $\begin{array}{l}\text { Yes } \\
(\mathrm{NLP})\end{array}$ \\
\hline $\begin{array}{l}\text { Zhang et al. [4] } \\
\text { (2018) }\end{array}$ & Yes & No & Yes & $\begin{array}{c}\text { Yes } \\
\text { (ANN) }\end{array}$ & No & Yes & No & No \\
\hline $\begin{array}{l}\text { Zafar and Mohanta [9] } \\
\text { (2018) }\end{array}$ & $\begin{array}{l}\text { Yes } \\
\text { (APF) }\end{array}$ & No & Yes & $\begin{array}{l}\text { Yes } \\
(\mathrm{ANN})\end{array}$ & Yes & Yes & No & No \\
\hline $\begin{array}{l}\text { Costa and Silva [17] } \\
\text { (2019) }\end{array}$ & No & No & $\begin{array}{l}\text { Yes } \\
\text { (GA) }\end{array}$ & No & $\begin{array}{l}\text { Yes } \\
\text { (RRT) }\end{array}$ & $\begin{array}{l}\text { Yes } \\
\left(\mathrm{A}^{*}\right)\end{array}$ & No & No \\
\hline $\begin{array}{l}\text { Patle et al. [10] } \\
\text { (2019) }\end{array}$ & $\begin{array}{l}\text { Yes } \\
\text { (APF) }\end{array}$ & No & Yes & Yes & $\begin{array}{c}\text { Only } \\
\text { mentions } \\
(\mathrm{PRM})\end{array}$ & No & No & No \\
\hline $\begin{array}{l}\text { Gómez et al. [18] } \\
\text { (2019) }\end{array}$ & No & No & No & No & No & No & $\begin{array}{l}\text { Yes } \\
\text { (eikonal } \\
\text { solvers) }\end{array}$ & No \\
\hline $\begin{array}{l}\text { Campbell et al. [19] } \\
(2020)\end{array}$ & Yes & No & Yes & Yes & No & No & No & No \\
\hline $\begin{array}{l}\text { Zhang et al. [20] } \\
\text { (2020) }\end{array}$ & Yes & No & Yes & No & Yes & $\begin{array}{c}\text { Yes } \\
\left(\mathrm{A}^{*} \text { Variants }\right)\end{array}$ & $\begin{array}{c}\text { Yes } \\
\text { (Fast } \\
\text { Marching) }\end{array}$ & $\begin{array}{l}\text { Yes } \\
(\mathrm{DP})\end{array}$ \\
\hline $\begin{array}{l}\text { Sun et al. [21] } \\
(2021)\end{array}$ & $\begin{array}{c}\text { Only } \\
\text { mentions } \\
\text { (APF, DWA) }\end{array}$ & No & $\begin{array}{c}\text { Only } \\
\text { mentions }\end{array}$ & Yes & $\begin{array}{c}\text { Only } \\
\text { mentions } \\
\text { (RRT and } \\
\text { PRM) }\end{array}$ & $\begin{array}{c}\text { Only } \\
\text { mentions }\end{array}$ & No & No \\
\hline $\begin{array}{l}\text { Vagale et al. [6] } \\
\text { (2021) }\end{array}$ & Yes & No & Yes & $\begin{array}{c}\text { Yes } \\
\text { (DRL) }\end{array}$ & $\begin{array}{c}\text { Yes } \\
\text { (RRT and } \\
\text { PRM) }\end{array}$ & No & No & No \\
\hline
\end{tabular}

\subsection{Path Planning Workspace Modeling}

A path planner needs to be fed with information describing the environment. This information can describe, for example, the presence of obstacles or the features of the surface that are relevant to the planning. In addition, the criteria used to calculate the path has to do with the way the robot interacts with this environment. For instance, merely to minimize path length and perhaps acquire the information as to what areas can be traversed or not is enough, whereas to minimize energy the terramechanics and the way the robot steers should be taken into account.

\subsubsection{Environment Modeling}

Surface mobile robots drive from one position to another within a certain region in space. Therefore, it is necessary to consider how the locomotion model will interact with this surface and how the path planner will take care of it. For instance, some algorithms require the construction of a graph that somehow represents the environment in which the robot is moving. This is mostly the case for Graph Search algorithms, part of the C-Space Search category. Evolutionary algorithms such as Ant Colony Optimizers (ACO) can also make use of a graph. This asset can represent how the terrain features that affect the robot navigation are spatially arranged in the scenario. In particular, the graph in question is assumed here to be built upon metric maps, acknowledging the existence of other kinds of maps outside of the scope of this paper, such as topological and semantic maps [22]. According to Souissi et al. [7] there are multiple ways to build a graph, as shown in Figure 2. The work of Nash and Koenig [11] has also shed some light onto this classification. It distinguishes between Cell Decomposition and Roadmaps. The first of these consists of tessellating the surface into cells. These cells can be arranged using regular $[3,4,7,11]$ or irregular grids $[7,11]$. Figure $2 \mathrm{a}-\mathrm{c}$ show how regular grids can be built using one out of three types of polygons: squares, triangles and hexagons. Its main advantage is the simple indexation of each node, which is translated into quick access to any of them and an optimized way to store them in memory [23]. Irregular grids, such as the one depicted in Figure $2 d$, allow the better adaptation the grid to terrain features with different values 
of resolution, at the expense of possibly obtaining worse paths [24]. Other forms of Cell Decomposition are the Navigation meshes and Circle-based waypoint graphs, as explained by Nash and Koenig [11]. The other form of representation of the environment is, as mentioned, accomplished using roadmaps. A roadmap is a graph built upon nodes connected by edges. Each node represents a possible state of the robot, whereas each edge indicates how to reach that state from another. Examples of roadmaps include Voronoi graphs [25] (see Figure 2e), Visibility graphs [26] and State-Lattice graphs (see Figure 2f). The latter consist of making the edges based upon motion primitives, so the resulting path is ensured to be feasible given the robot mobility constraints, especially when using Graph Search algorithms, as in the work of Likhachev and Ferguson [27], Bergman et al. [28].

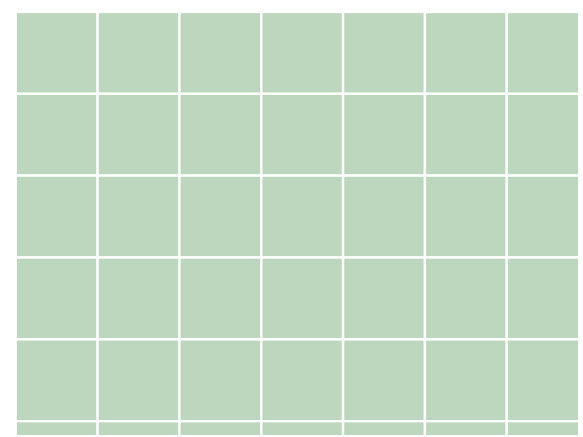

(a)

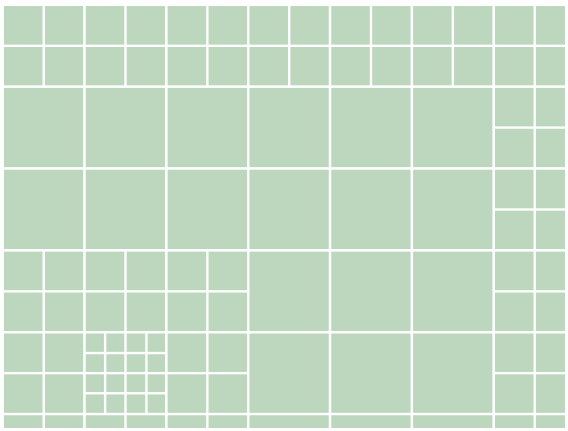

(d)

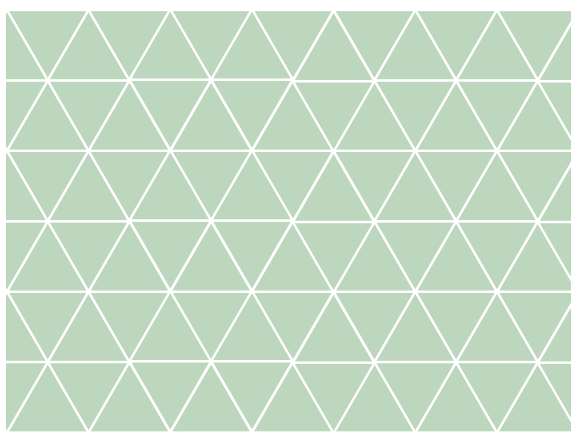

(b)

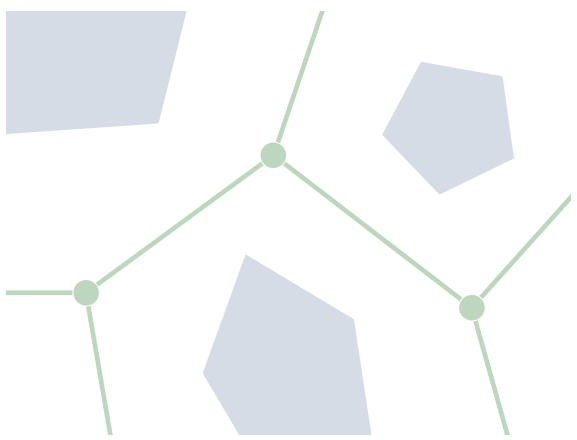

(e)

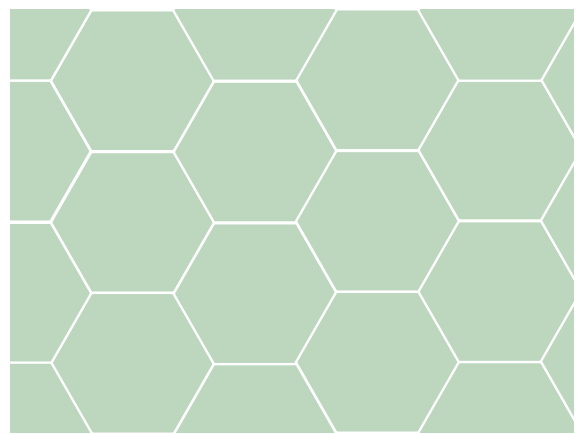

(c)

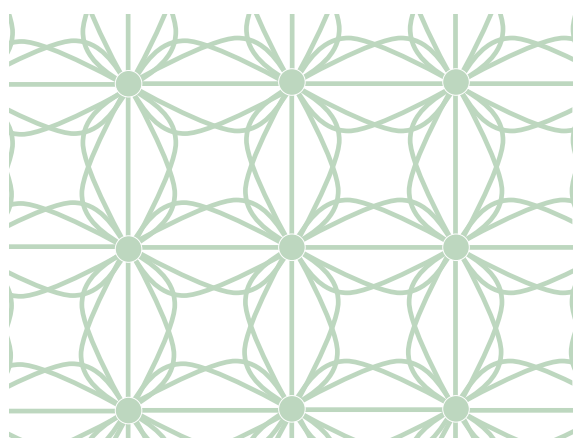

(f)

Figure 2. Different types of environment cell decomposition (a-d) and roadmap graphs (e-f). (a) Tessellations using squares. (b) Tessellations using triangles. (c) Tessellations using hexagons. (d) Irregular grid. (e) Voronoi roadmap. (f) State lattice graph.

The cells or the nodes from these graphs can store information regarding the surface at their location, in the form of static or dynamic elements [10]. This can be, for instance, elevation information. A Digital Elevation Map (DEM) is a grid of which the nodes have associated with each of them a value of elevation. Elevation maps can be also represented by polygons, but regular grid maps are preferred [29]. Shape-related features, such as the slope or the surface roughness, can be extracted using convolution matrices [30]. The size of the kernel and the DEM resolution will determine what kind of features are extracted. Moreover, this resolution defines the level of detail of the elements contained in the map. As shown in Figure 2d, this resolution can be non-uniform or multiple. The size of the grid can be chosen according to the scale at which the planning is performed: Local in the case of covering the immediate surroundings of the robot (more or less the reachable distance of the on-board sensors) and Global if the area is bigger than that, usually using information from external sources such as satellites or drones.

With regards to how the cost is defined over the planner workspace, there are different ways. First of all, we understand cost as the metric that the robot accumulates by moving. The objective of the path planner is to minimize this accumulation by producing the optimal path. The cost in question can be uniform, in the sense that the regions that can be accessed 
by the robot always have the same value. This approach can be used for collision-avoidance path planning, in which metrics such as the path length in a 2D plane are minimized. Nonuniform cost maps can be used to assign different values of cost to different accessible areas. It can be useful to, for example, define the energetic performance of the robot at each location. Moreover, the cost can be also defined according to a direction vector. This means that the robot will experience different values of cost depending on its heading. In this case, the cost is categorized as anisotropic [31], whereas in the contrary case the cost is isotropic. Furthermore, the steering manoeuvre of the robot can also have different values of cost according to its locomotion. Finally, it is worth noting that the environment can be fully known, partially known or even fully unknown, requiring for the latter two a planning strategy that is capable of replanning when this knowledge is updated.

\subsubsection{Robot-Surface Interaction Modeling}

A ground mobile robot interacts with the surface beneath it to propel itself. To perform this function, there are many different locomotion actuators, such as wheels, tracks, legs and even omnidirectional wheels. Figure 3 depicts three real examples of ground mobile robots using different configurations of actuators. These actuators, together with the joints linking them to the robot body, determine the kinematic structure and the dynamic behavior of the robot. In other words, they determine the locomotion configuration of the robot. Zhang et al. [20] summarize some kinematic and dynamic models of different well-known configurations: Differential drive [32] (see Koguma robot [33] in Figure 3a as an example and the depiction of the model in Figure 4a), Ackermann steering [34] (see Figure 4b,d), Skid steering [35] (see Figure 4c) and Omnidirectional [36]. Some of them entail constraints relevant to path planning, such as the minimum turning radius of robots with Front Ackermann steering [37] (see Figure 4b) or the high energy consumption of Skid-steering robots in turning manoeuvres [38]. Moreover, another model exists, called Crabbing (see Figure 4e). It allows a robot to drive in a direction different to the one it is facing, due to having steering joints on top of all wheels [39]. Furthermore, some kinematic configurations allow the robot to perform the Point Turn manoeuvre, which makes them rotate without translating. It is worth mentioning the existence of articulated robots that are capable of reconfiguring themselves to obtain some kind of benefit and perform multiple types of locomotion (see SherpaTT in Figure $3 \mathrm{c}$ as an example of this). For instance, articulated robots with tracks can actively control their stability while driving on rough terrains [40,41]. Others use a wheel-on-legs configuration to execute a locomotion mode called Wheelwalking $[42,43]$. This mode is designed to overcome soft terrains in which a robot could get stuck. In a similar way, Push-pull locomotion imitates the motion of a caterpillar to increase traction in this kind of terrain [44-46]. Path planning algorithms acknowledging this reconfiguration capability are a must-have for this kind of robot, as they can find paths that take advantage of their high adaptability. In the case of global planning, Rohmer et al. [47] used a Graph Search algorithm, Dijkstra, to first produce a path and later, via simulation tools, evaluate which locomotion mode is better to drive each of its parts. We, the authors of this review publication, proposed the use of a PDE Solving method to consider the multiple locomotion modes at the time of planning using an isotropic cost function [48,49]. To the authors' knowledge there are not many existing Local Planning approaches addressing the kinodynamic constraints of robots with multiple locomotion modes. Reid et al. [50] proposed the use of a Sampling-Based algorithm, the Fast Marching Tree (FMT*), to tackle the motion planning of a reconfigurable hybrid robot with wheeled-legs.

The robot's locomotion will adapt better or worse depending on the terrain features, which were briefly mentioned before. These features may be related to either the morphology (shape) or the composition of the terrain. One of them is the terrain inclination or slope [51]. The slope has an influence on the Roll and Pitch orientation angles of the robot, which is important to consider to preserve stability [41,52,53]. Moreover, it can also influence the energetic performance of the robot according to its direction. This dependency on direction is due to the effect of gravity, making the robot consume different amounts of 
energy according to whether it is climbing, descending, going laterally or going diagonally through the slope $[29,54-57]$. Another relevant terrain feature is the roughness. This is the measure of how diverse the normal vectors are [58,59] and may affect the vibration experienced by the robot. Other terrain shapes can be negotiated by the robot, according to its chassis. For instance, it can overcome rocks using the body clearance, which is the space between the body lower surface and the terrain surface $[60,61]$. The presence of negative obstacles such as holes or ditches can be problematic as they are difficult to capture by the robot's sensors [62]. With regards to the terrain composition, it has an influence on the dynamics underlying the robot-surface interaction. This surface may be more rigid or deformable [63]. This affects the way the robot adheres to the surface, even restricting its motion [64]. The slippage is the metric that, in general terms, measures how the real speed of the robot differs from the commanded one, usually by calculating a ratio between them $[65,66]$. Some works consider both slippage and the slope of the terrain to make a more accurate estimation of the robot while traversing rough terrains $[67,68]$. The magnitude of gravity can also affect the dynamics of the interaction between the robot and the terrain $[30,69]$. Finally, path planners usually make use of cost functions that encompasses multiple terrain features related to shape and composition. For instance, Ishigami et al. [2] introduced the dynamic mobility index, encompassing stability, slippage, elapsed time and energy consumption. Moreover, there may exist other elements not directly related to the terrain that may still affect the performance of the robot while navigating. One of them is the solar radiation [66,70], which can be modeled as a dynamic function [71]. Groves et al. [72] mapped other kinds of radiation that may harm the robot, as in scenarios of nuclear dismantlement. Moreover, the concept of risk can be of high importance to prevent the robot from getting into a dangerous situation [73], such as increasing the cost with the proximity to obstacles [74].

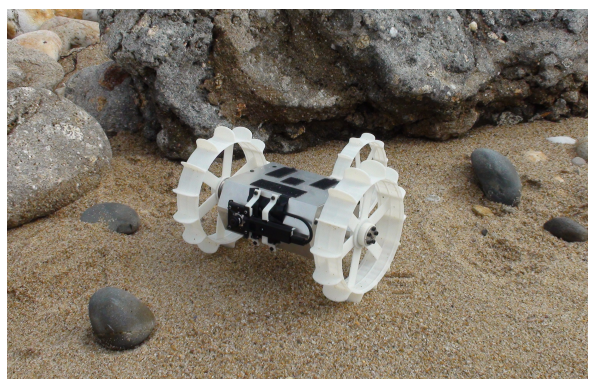

(a)

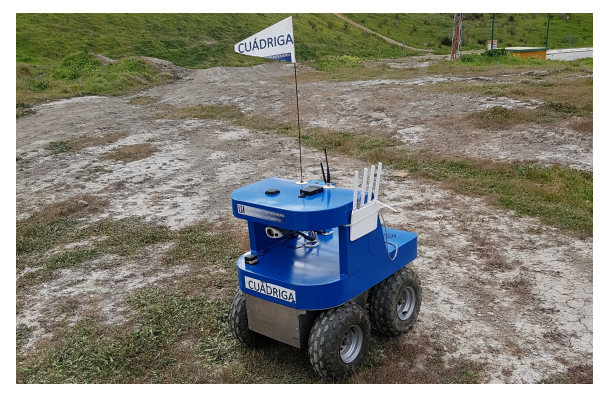

(b)

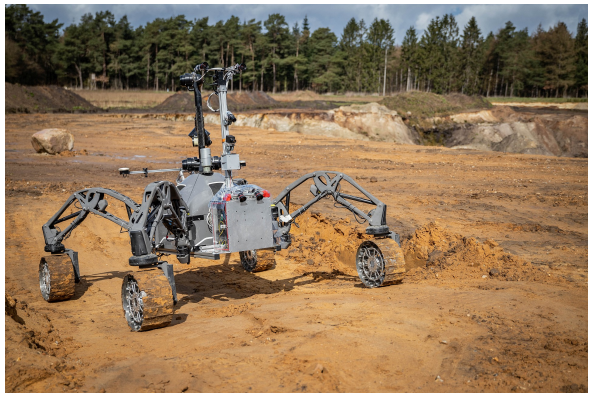

(c)

Figure 3. Examples of ground mobile robots with different kinematic configurations. The Koguma rover (a) has Differential Drive locomotion. Cuádriga (b) is a Skid-steering robot owned by our institution, the University of Málaga. SherpaTT (c) has four steerable wheels that allow it to execute Full Ackermann, Crabbing and Point Turn maneuvers. (a,c) have been reproduced with permission of the University of Tohoku and the German Research Center for Artificial Intelligence (DFKI), respectively.

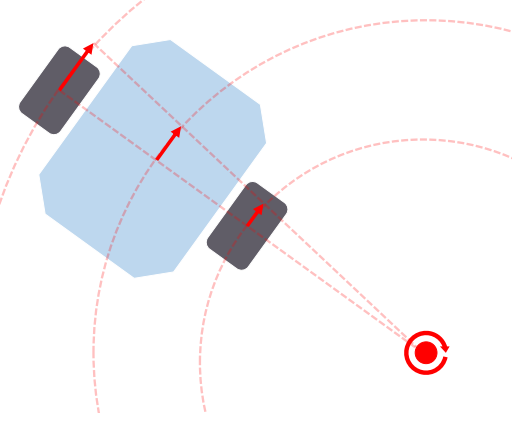

(a)

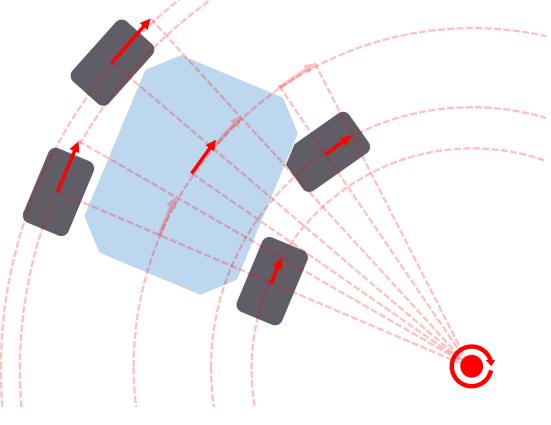

(b)

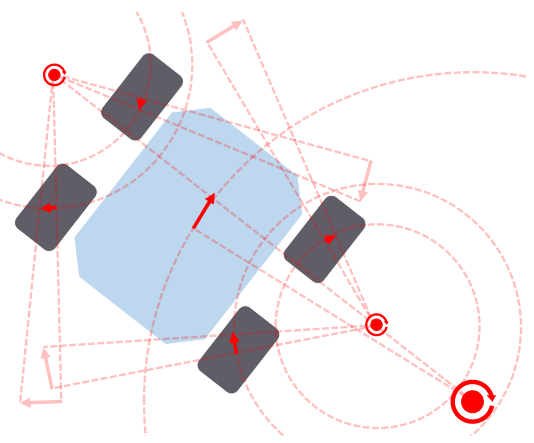

(c)

Figure 4. Cont. 


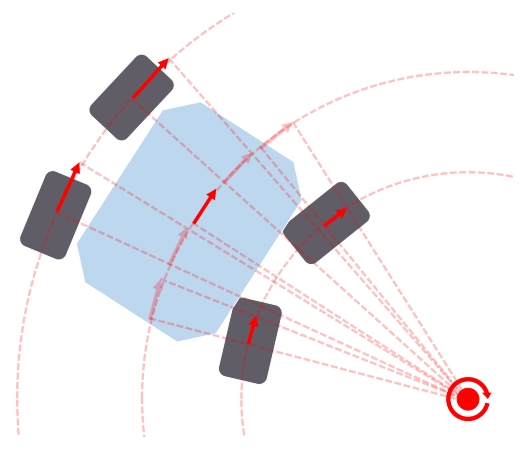

(d)

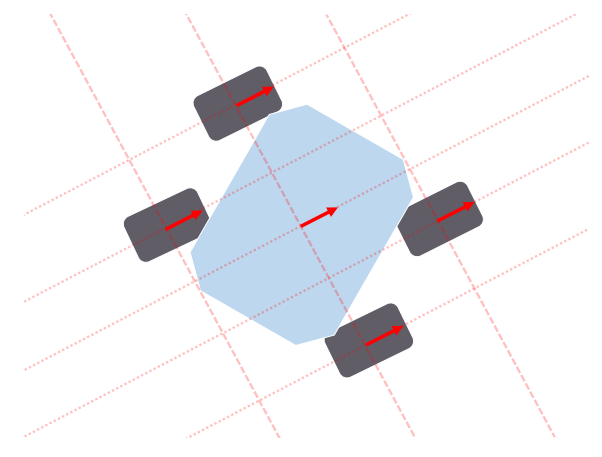

(e)

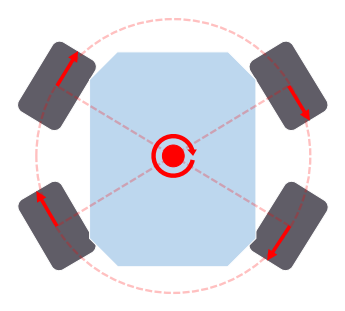

(f)

Figure 4. Locomotion models used for wheeled ground mobile robots along with path planners: Differential drive (a), Front Ackermann (b), Skid-steering (c), Full Ackermann (d), Crabbing (e) and Point Turn (f).

\section{Reactive-Computing-Based Path Planning Algorithms}

This category encompasses path planning algorithms where the environment, usually a map distinguishing between obstacle and non-obstacle regions, only indicates the location and shape of the existing obstacles. Reactive Computing algorithms are usually employed as local path planners (covering the surroundings of the robot and with dynamic replanning) due to their capability to quickly handle new information (e.g., in the form of newly discovered obstacles), which often comes from the limited onboard sensors. As local planners, these algorithms usually plan the next immediate path or manoeuvre to avoid nearby obstacles while following a global plan made by another algorithm. However these algorithms may calculate local minima paths, or even cause the robot to get stuck, so special care must be taken. There are two subcategories of Reactive Computing algorithms: Reactive Manoeuvre methods, where the presence of obstacles determines the immediate next manoeuvre of the robot, and Local Optimization methods, where an existing path is modified according to the presence of obstacles.

\subsection{Reactive Manoeuvre}

The algorithms presented here rely on defining how the robot reacts at each instant to the presence of obstacles. This reaction can be defined according to a formulation that addresses the location of existing obstacles. A common feature of the different formulation approaches is the low computational requirements needed to produce the reaction, usually in the form of a steering or velocity command. Since this formulation lacks global information, these techniques are commonly used as Local Planners. The formulation in question may be based on the use of fields to tackle the location of obstacles, the detection of obstacle boundaries to circumvent them, or the production of a velocity command after evaluating the available free space or the speed of moving obstacles.

The use of field methods include the Artificial Potential Fields (APF) and the Vector Field Histogram (VFH) algorithms. In APF, the motion of a robot can result from the sum of virtual forces that external elements such as obstacles create. In this way, the robot gets further from these obstacles and avoids colliding with them, as the forces from them are repulsive [75]. An attractive force created by the target position makes the robot go towards it. This can be seen in the picture displayed in Figure 5a. Ge and Cui [76] presented an application of APF in environments containing dynamic obstacles. However, the main drawback of this strategy is that it is prone to causing the robot to get stuck in local minimum points. For this reason, further research works were oriented to overcome this issue. This was the main target of the work by Vadakkepat et al. [77]. They combined APF with genetic methods (Evolutionary algorithms) to overcome this situation. This combination was also used to plan the motion of a simulated 6-wheel rover [78]. Another hybrid version includes the use of PSO algorithms [79]. Triharminto et al. [80] proposed a non-hybrid solution, consisting of adding a repulsive potential field around the rover. However, it has not yet been tested with U-shaped obstacles. Other works solve this 
issue by creating custom escape paths whenever it is detected that the robot is on a local minimum point [81]. Furthermore, Bayat et al. [82] present a solution inspired by electrostatic potential fields in which, instead of using a sum of virtual forces, a so-called scalar potential field guides the robot. VFH, proposed by Borenstein et al. [83], creates a polar histogram to evaluate the density of obstacles around the robot, selecting the steering angle with the lowest density of obstacles. Some improvements to VFH were introduced years later $[84,85]$.

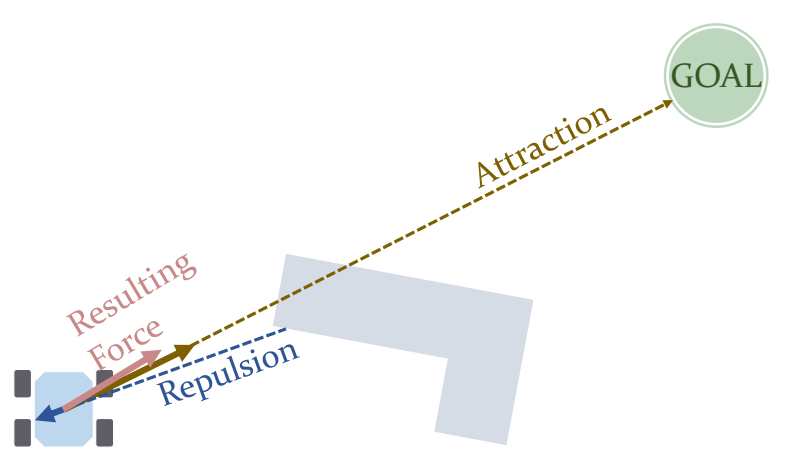

(a)

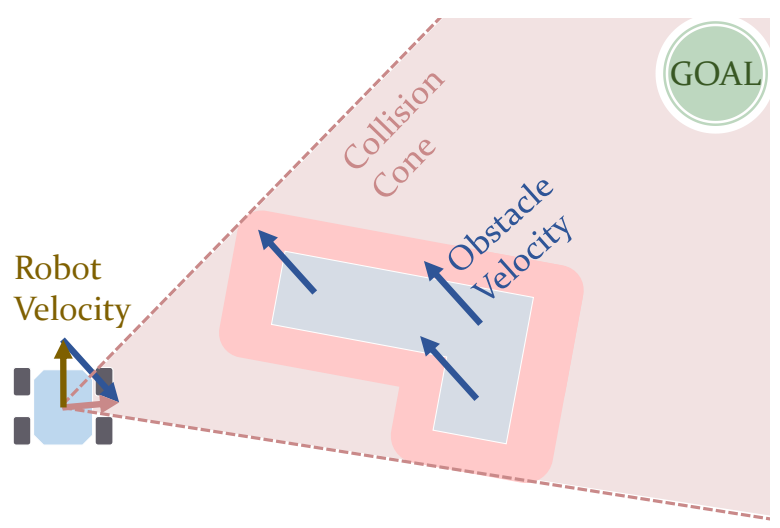

(b)

Figure 5. Graphical representations of concepts used in Artificial Potential Field (a) and Velocity Obstacle (b) algorithms. (a) Potential fields acting on a robot. (b) Collision cone considering a moving obstacle.

The Bug algorithms, Bug1 and Bug2, make the robot circumvent any obstacle found on its way until it reaches the goal [86]. The main difference between them is that Bug1 makes the robot drive the full boundary of any obstacle (see Figure 6a), whereas Bug2 can drive it only partially [19]. They despise optimality in favour of easiness in the implementation and very minimal computation. They can be used on robots equipped only with sensors that just detect obstacles in their immediate vicinity. In this way, these robots either drive towards the goal or drive along the boundaries of obstacles they find. The works of Buniyamin et al. [87] and Campbell et al. [19] refer to some variants that improve this kind of algorithm, in general reducing the distance the robot drives. $\mathrm{Xu}$ et al. [88] uses the Bug algorithm considering turning radius constraints, producing paths with smooth turns.

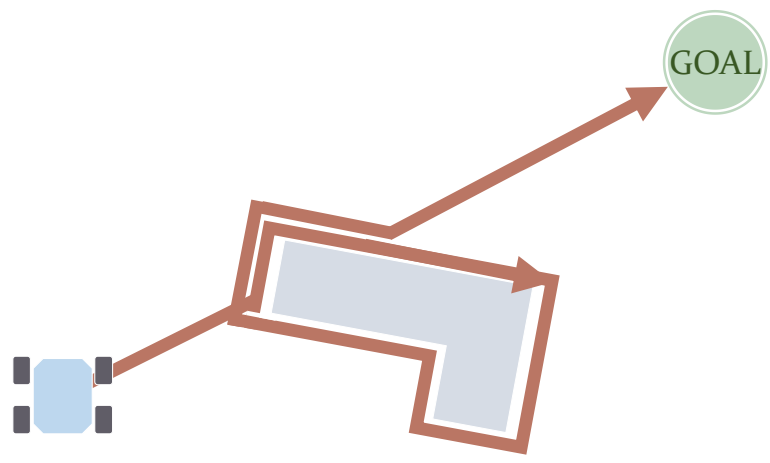

(a)

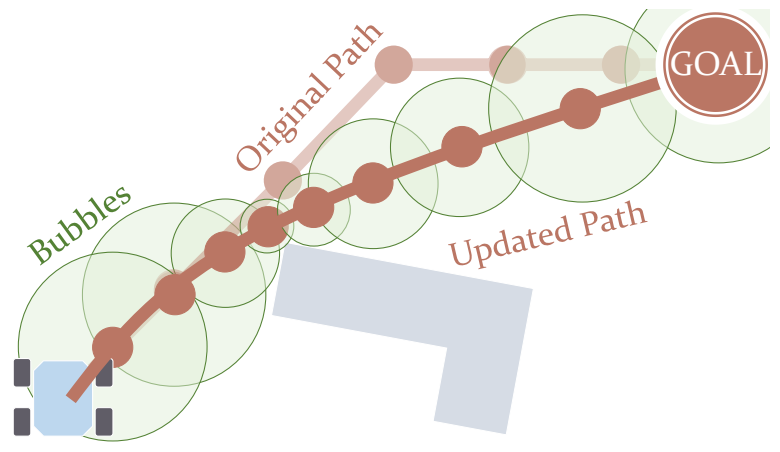

(b)

Figure 6. Graphical representations of concepts used in the Bug algorithm (a) and Elastic Bands (b) algorithm with Bubble bounds. (a) Path after using the Bug1 algorithm. (b) Path after experiencing stretching.

The following approaches are focused on producing a velocity command for the robot. Velocity Obstacles methods calculate a safe trajectory considering the velocity vectors of both the robotic agent and any other moving obstacle [89,90]. This calculation evaluates a cone of collision such as the one shown in Figure 5b. Chen et al. [91] used Velocity Obstacles in an hybrid fashion with another algorithms called Fast Marching 
Square (FMS). Wilkie et al. [92] considered the Front-ackermann (see Figure 4b) locomotion model for cars. Chakravarthy and Ghose [93] proposed using a Collision-cone algorithm, similar to Velocity Obstacles but considering obstacles with arbitrary shapes. Qu et al. [94] introduced its use along with car models (with Front-ackermann configurations, as seen in Figure 4b). Finally, the Dynamic Window Approach (DWA) is an algorithm that searches in the velocity space for a velocity command to follow a collision-free circular trajectory, delimited by admissible speed values and a time window [95]. This solution may not be the globally optimal one, but rather a locally optimal one [4]. DWA can be used even for robots navigating at high speeds [96]. Feng et al. [97] propose an improved version that reduces its complexity by reducing the velocity space to search. Other approaches use this algorithm for energy-minimization path planning [98,99]. Although commonly used as a local planner, Zhang et al. [5] have proposed its use at a global scale as a global path planner.

\subsection{Local Optimization}

These algorithms usually start from a pre-existing path and modify it according to the existing obstacles. Here it is prioritized to keep computational use to the minimum at the expense of losing optimality or even completeness. There are different options to modify the path, ranging from the selection of velocity profiles within a velocity space to the stretching and elongation of the path under the effect of artificial forces.

The use of Elastic Bands in path planning was proposed by Quinlan and Khatib [100]. This method deforms an existing collision-free path according to the obstacles, stretching (see Figure 6b) or elongating it. From a set of points in this path, a set of overlapping subregions, called Bubbles, is created. These Bubbles cover collision-free areas and their size is bounded by the distance to obstacles. This entails that smaller and more numerous Bubbles are present in the portions of the path closer to obstacles. It can be used in dynamic environments, although large changes may lead to the failure of the method [100]. Moreover, it has also been adapted to non-holonomic vehicles by complying with curvature constraints Khatib et al. [101] and using Bezier curves [102]. An extension to Elastic Bands includes time constraints and is named Timed Elastic Bands (TEB). This extended version addresses the kinodynamic constraints of the robot [103].

\section{Soft-Computing-Based Path Planning Algorithms}

This kind of algorithm does not intend to find the exact optimal solution, but rather to approximate it, tolerating a certain range of imprecision. In general, these algorithms require the tuning of certain parameters by the user in order to work properly according to the characteristics of the environment. They can deal even with dynamic environments and are adequate for problems involving a large number of variables and high degrees of freedom [8]. However, in general they demand a high number of computational resources. This review follows the classification proposed by Mirjalili and Dong [104], which distinguishes between Evolutionary, Fuzzy control and Machine learning methods. The first one uses techniques inspired by biology and nature: they start with a system formed by individuals that changes over time, i.e., evolves. Fuzzy control and Machine learning methods are here part of a subcategory named Artificial Intelligence. They use fuzzy rules and neural networks, respectively, to produce controllers. These controllers are very useful for navigating through initially unknown scenarios and in general produce paths according to the obstacles the robot detects on its way. To sum up, Soft Computing algorithms allow the tuning of a series of repetitive elements, either nature-based individuals, fuzzy rules or artificial neurons, to generate a path.

\subsection{Evolutionary Computation}

Evolutionary algorithms are also known as Meta-heuristic or Nature-inspired [105]. These algorithms generate a path that results from the evolution of a population. This population is made up of intelligent individuals whose actions are modelled after behaviors 
found in nature [104]. These actions may involve modifying themselves and/or interacting with other individuals. In some cases, these operations imply a motion by the individuals in the free space of the environment, i.e., in the space reachable by the robot. After performing a series of these operations, the algorithms approximate the optimal solution. The resulting path and the time invested to converge depend on the behavior policy assigned to the individuals, the nature of the scenario and the values assigned by the user to certain configurable parameters. An example of the latter is the number of individuals that populate the path planning problem. Evolutionary algorithms include Genetic methods and Swarm Optimizers. The first method uses chromosome models, whereas the second one models the behavior of living beings.

As just mentioned, Genetic algorithms work with individuals modeled after chromosomes [106]. These individuals contain genes, as chromosomes do, in the form of binary numbers. These numbers encode a solution, which is the set of waypoints forming a path in the particular case of solving the path planning problem. In other words, each chromosome in the population represents a path. Figure 7a depicts an example using a grid. This grid is made up of cells, each of them labeled with a number. The genetic algorithm starts with a random set of chromosomes. This set evolves using three processes: Reproduction, Crossover and Mutation [107]. Reproduction creates new chromosomes by copying the best ones. It also removes the worst ones. Crossover is the process in which chromosomes interchange their genes. Mutation introduces random changes in the genes to incentive the exploring of the search space and to avoid local minima. As a result of continuously repeating these processes, the algorithm converges. Zhang et al. [4] mention Genetic algorithms that converge more slowly as they get closer to the optimal solution. Han et al. [108] used Genetic algorithms to find the shortest paths in environments with dynamic obstacles. Tuncer and Yildirim [109] presented a modification to the Mutation process. This consists of checking free nodes around the position that is about to be mutated. This work compares the results with previous variants of the method. Another research work used genetic algorithms, along with large grids up to $2000 \times 2000$ nodes [110]. Genetic algorithms for path planning were also tested on an experimental platform [111]. More improvements include the initial selection of waypoints, considering those located near obstacles [112]. Elhoseny et al. [113] introduced a more regulatory policy on exploration during Mutation, taking into account how diverse the chromosomes are. Furthermore, this work not only optimized path length but also preserved smoothness using Bézier curves. Finally, the Crossover process is also improved upon in the work of Lamini et al. [114] to make the solution converge faster and also to reduce the number of turns made by the robot. There are many path planning applications based on Genetic methods presented in the review of Patle et al. [10].

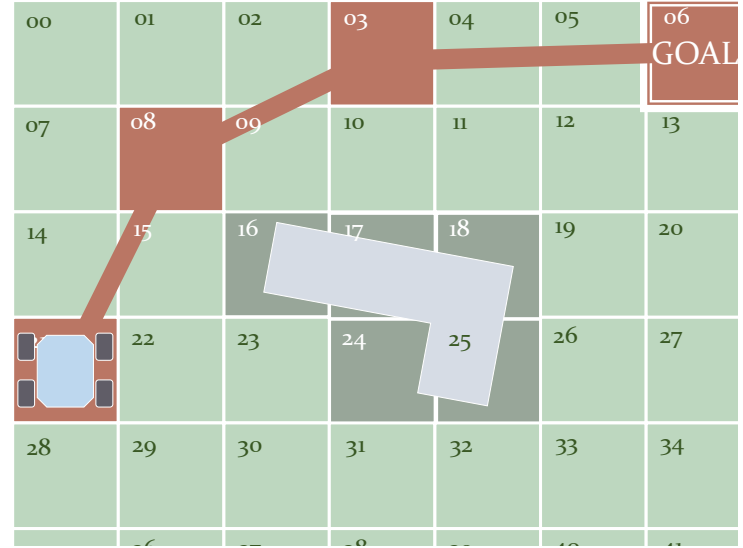

(a)

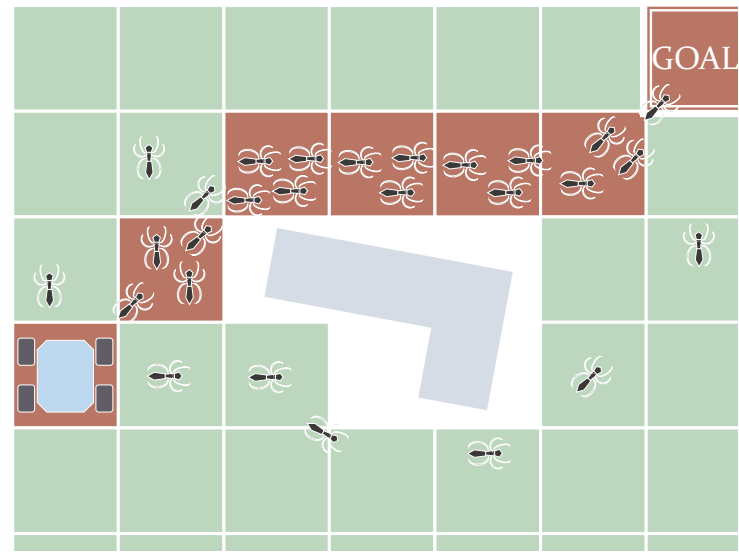

(b)

Figure 7. Examples of Evolutionary algorithms: Genetic (a) and Swarm Optimizer ACO (b). (a) Functioning of the genetic algorithms used to perform path planning. The path in this figure has the form of a chromosome with genes 21-08-03-06. (b) Functioning of the ACO algorithm. Simulated ants deposit more pheromones in the shortest path. Eventually the majority will follow this path. 
Unlike the algorithms based on Genetic methods, Swarm Optimizers use agents that move and actuate in the free space. These individuals are modeled after animals in most cases. After a series of iterations, the motion of these individuals towards the goal creates a pattern that eventually converges to the resulting path. Table 2 introduces some of the models used that can be found in the literature. The Particle Swarm Optimization (PSO) algorithm stands out because of its simplicity. It is inspired by the behavior of certain groups of animals such as fish schools [115]. It creates a series of particles that relocate themselves over time until the algorithm converges. These algorithms search for the best positions and communicate with each other, considering their previous experience [116]. Mac et al. [117] propose a path planner that combines PSO with the Dijkstra algorithm (a Graph Search planner that is discussed below). Another well-known algorithm is the Ant Colony Optimizer (ACO) which, as the name indicates, simulates the behavior of ants. These insects move while leaving a trail of pheromones in their search for food. This trail can be tracked by the rest of the ants. Those places that contain more pheromones make up the waypoints of the best-found path. Figure $7 \mathrm{~b}$ depicts this concept in a situation with an obstacle between the start and goal positions. Here, the best path is the shortest one. Following the same strategy, virtual ants can move on a grid, leaving more or fewer pheromones according to their state concerning the goal $[118,119]$. To avoid falling into a local minimum, some works combine this method with heuristic functions $[120,121]$. Che et al. [122] also solve this by adopting a rule used in the Grey Wolves approach. Luo et al. [123] present some improvements for ACO to not only avoid deadlocks but also to reduce the time it needs to converge. This algorithm has also been simulated with DEMs to minimize time [124] and energy [125]. The latter has also been achievedwhile avoiding dynamic obstacles, which is also addressed by the work of Sangeetha et al. [126]. This work combines ACO with fuzzy control. There are plenty more nature-inspired approaches. To avoid extending too much, some of them are indicated in Table 2. Moreover, there are also cases in which two models are combined. This is the case of the approach presented by Saraswathi et al. [127], where a hybrid between Cuckoo and Bat algorithms is tested.

Table 2. Intelligent models used for some swarm algorithms, together with some of the models.

\begin{tabular}{ll}
\hline Individuals & Behaviors \\
\hline Particles [115-117,128] & Best position memory, variable velocity \\
Fireflies [129] & Brightness atraction \\
Dragonflies [130] & Hunting and migration \\
Grasshoppers [131,132] & Attraction and repulsion \\
Wolves $[133,134]$ & Hierarchy system, hunting for prey \\
Whales [135,136] & Spiral bubble-nets \\
Cuckoos [137] & Lévy flights, brood parasitism \\
Bats [138] & Echolocation \\
Bacteria [139] & Foraging \\
\hline
\end{tabular}

\subsection{Artificial Intelligence}

Soft Computing algorithms may use other sets of configurable operators such as fuzzy rules or neural networks. Seraji and Howard [140] demonstrate the use of fuzzy logic on an experimental mobile platform to navigate through unstructured terrain. Zavlangas and Tzafestas [141] provided a fuzzy-logic-based system designed to make a mobile robot autonomously navigate through a dynamic environment, avoiding obstacles on its way. The work of Wang et al. [142] focuses on preventing the robot from getting stuck in local minimum points, such as those produced by U-shaped obstacles. Pandey et al. [143] also provides the results of simulation tests of fuzzy logic for obstacle avoidance. With regards to the use of neural networks, Yan and Li [144] also use fuzzy logic on a platform focusing on minimizing computational resources and traversing environments containing dynamic obstacles. Pandey and Parhi [145] combines fuzzy logic and a population-based algorithm named Wind Driven Optimization that tunes the fuzzy rules. With regards to the use 
of neural networks, Zou et al. [146] presented a brief survey on this kind of algorithm for applications at the beginning of the 2000s. Engedy and Horváth [147] presented a path planner using neural networks for mobile robots that must avoid static and dynamic obstacles. Zhang et al. [148] used this kind of technique to find the shortest path in maze scenarios. This approach has also been used together with genetic algorithms $[149,150]$.

Other works in the literature combine fuzzy logic and neural networks [151-154]. There have been different approaches to this. For instance, Mohanty and Parhi [155] use many of these systems for autonomous navigation. Further insights and a more extensive surveys on related hybrid methods are provided in Mac et al. [8]. Furthermore, the use of Reinforcement Learning (RL) has also been studied to control the motion of a robot [156,157]. Faust et al. [158] combined RL with the Probabilistic Roadmap Method (PRM), which is one of the algorithms detailed next. For more information about planning algorithms based on RL, refer to the work of Sun et al. [21].

\section{C-Space-Search-Based Path Planning Algorithms}

Algorithms in this category consider the working space of the path planner as the space of all states or configurations reachable by the robot. For this reason, most of the works in this category refer to this working space as the C-Space. The main idea behind these algorithms is to use a discrete set of samples that are part of this C-Space. In other words, the C-Space is discretized. This set of samples includes the initial and the goal states, or at least samples relatively close to them. In this way, these algorithms execute a search operation, visiting samples from this set. At a certain point, the algorithm will find and return a certain subset of samples connecting the initial and goal states representing the resulting path. In other words, the waypoints forming the paths correspond, each of them, to a sample from the C-Space. This implies that the generated path heavily depends on how these samples are scattered, how they are connected and how are they visited. In fact, due to this dependency, in some approaches post-processing is done to smooth the shape of the resulting path.

The C-Space Search category is subdivided into two groups of algorithms according to how they discretize the C-Space. Graph Search algorithms do this using a pre-existing graph (such as one of those depicted in Figure 2). Each of the nodes from this graph represents a C-Space sample and is connected to other nearby nodes, i.e., its neighbors. With regards to Sampling-Based algorithms, they focus on the creation and/or modification of samples within the C-Space in an iterative way. They can keep working, even after finding a feasible path, to find better ones.

\subsection{Graph Search}

As mentioned, the C-Space can be discretized in the form of a graph. Graph Search algorithms fully or partially visit this graph until they find a path connecting the initial and goal states. The first algorithms made in this category return paths of which the waypoints are placed on top of neighboring samples. In other words, the connections between consecutive waypoints of the path are coincident with the graph edges. Figure 8a depicts a schematic showing how in the first case the shape of the path is determined by these edges. This review, therefore, categorizes the Graph Search algorithms generating this kind of path as Edge-restricted. These paths consequently depend on how the graph is structured. As seen in Section 2.2.1 there are various graph structures in the form of Cell Decomposition and Roadmaps. Another kind of Graph Search algorithm, Any-angle, were created to solve this issue with the restriction to the graph edges. The reason this name is used is that paths produced by Edge-restricted planners only use certain values of orientation. For example, in an eightneighborhood regular grid, as in the case shown in Figure 8a, Edge-restricted paths can only have orientations with $0, \pm 45, \pm 90, \pm 135$ and 180 degrees. Any-angle algorithms produce paths that are not restricted to these orientations as their waypoints do not necessarily have to be placed in neighboring nodes. Figure $8 \mathrm{~b}$ depicts an example of this. 


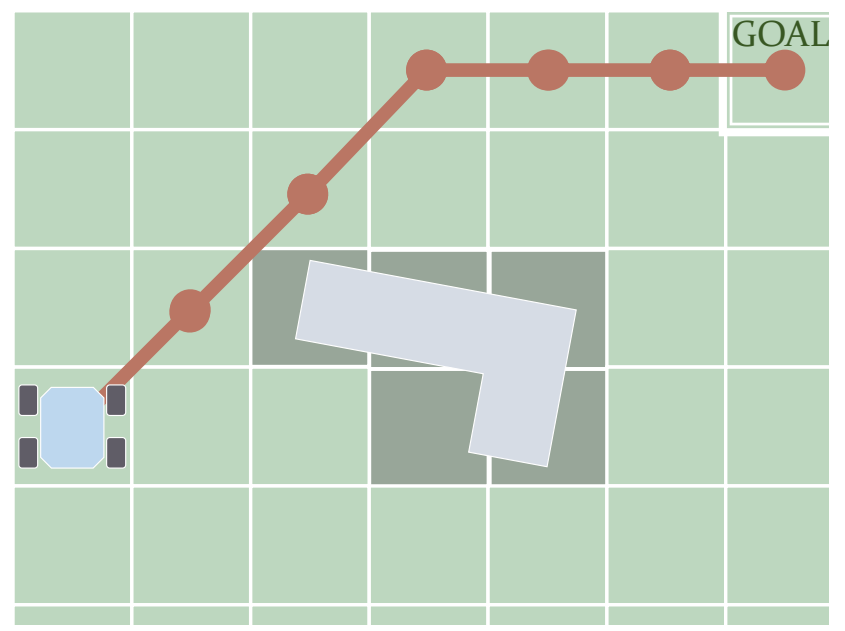

(a)

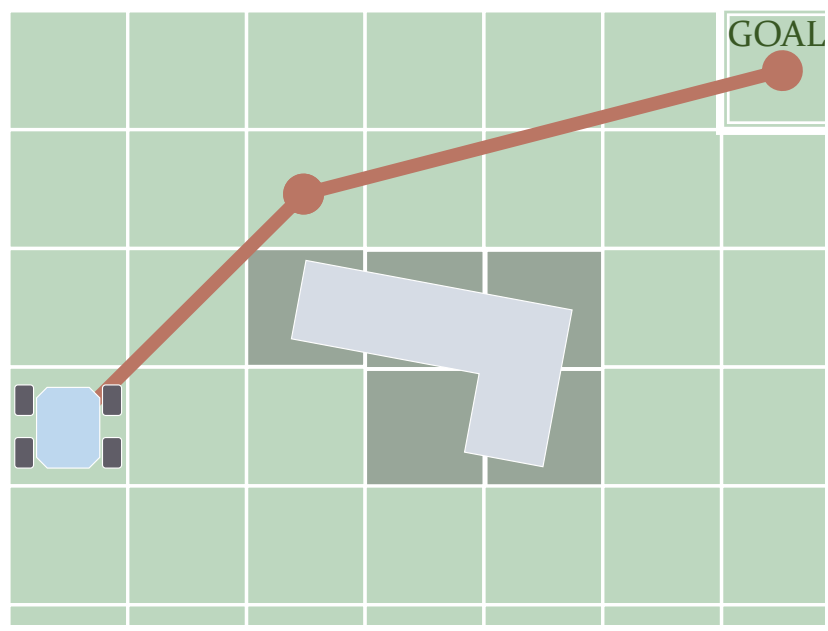

(b)

Figure 8. Main difference between the paths (in red) produced by Edge-restricted (a) and Any-angle algorithms (b): in the first case, waypoints can be placed only on consecutive (neighboring) nodes.

With regards to Edge-restricted algorithms, Figure 9 shows a schematic with the most representative versions of them that can be found in the literature. The most known and basic Edge-restricted path planner is the Dijkstra algorithm [159]. As an initial step, this algorithm takes one node, either the start or the goal. Thereafter, it proceeds to propagate information to its neighbors. It could be either the value of the cost required to arrive from the start or the one that remains to arrive at the goal. Iteratively, the algorithms visit the neighbors of already-visited nodes. The information about the amount of cost keeps propagating, and the algorithms assign to each visited node a parent node. If the environment allows it, i.e., no obstacles are isolating either the goal or the start, the algorithm ends up visiting both of them. At this point, the path is retrieved by backtracking the parent nodes. In other words, the path starts from the last visited node and goes back through the parent nodes. Years later, Hart et al. [160] implemented a heuristic version, $A^{*}$, to speed up computation. Later on, further improvements were introduced. $\mathrm{D}^{*}$, also named Dynamic $A^{*}$, was introduced by [161] as an incremental version of $A^{*}$. The fact that it is incremental means that this algorithm recycles previous computations whenever there are changes in the cost assigned to the grid nodes. This prevents the algorithm from executing a whole new computation from scratch. This reduction in the computation allows for rapid replanning in cases where the robot encounters novel obstacles on its way, for example. An improved version called Focussed $\mathrm{D}^{*}$ managed to further reduce the computation time of $\mathrm{D}^{*}$ [162]. Koenig and Likhachev [163] propose the use of Lifelong Planning $\mathrm{A}^{*}\left(\mathrm{LPA}^{*}\right)$ as another direct incremental extension of $\mathrm{A}^{*}$. This was taken into account as a reference to produce a much simpler version of $D^{*}$ called $D^{*}$-Lite [164,165]. Colas et al. [166] employed this algorithm on mobile robots in search-and-rescue applications. Since $\mathrm{A}^{*}$ and $\mathrm{D}^{*}$ algorithms, including their versions, make use of heuristic functions, the resulting paths can be sub-optimal. Likhachev et al. [167] propose anytime versions of these algorithms, which use a configurable fixed time. The best path found, at a given time, is generated by these anytime versions. Dolgov et al. [168] propose a version of $\mathrm{A}^{*}$, Hybrid $\mathrm{A}^{*}$, that prioritizes the feasibility of the resulting paths in exchange for the loss of optimality and completeness by rearranging the nodes after a path is found; in a way, the path is kinematically feasible.

With regards to the Any-angle algorithms, one of the first ones was Field- $\mathrm{D}^{*}$ [169]. This is a well-known algorithm mainly due to its use on Mars NASA rovers since Spirit and Opportunity [170]. Similarly to $\mathrm{D}^{*}$ and $\mathrm{D}^{*}$-lite, it is an incremental algorithm, so it recycles previous computations in subsequent executions. Although Field-D* arose as an outstanding method to overcome the problem of paths restricted to edges, there was still a margin to improve the results and find even more optimal paths. Years later, more Any-angle algorithms were created having $A^{*}$ as a basis, focused on the problem of finding the shortest paths 
while avoiding obstacles. Nash et al. [171] created Theta* for this purpose. They presented it in two versions: one computationally cheaper, Base-Theta*, and another more expensive but with results closer to the globally optimal shortest path, named Angle-Propagation Theta* $^{*}$ The main premise behind Theta* was the consideration of heading changes on obstacle corners, reducing these changes along the path in contrast with Field- $D^{*}$ [172]. An incremental version of the Base-Theta* algorithm was later introduced with the name of Incremental Phi* [173]. A faster version of Theta*, Lazy-Theta*, was introduced by Nash et al. [174]. Theta* was also improved to work better on non-uniform cost maps, where the cost increases the closer it gets to obstacles [175]. The Accelerated $\mathrm{A}^{*}$ algorithm was introduced by Šišlák et al. [176]. It finds shorter paths than Theta* but at a slower rate (although still faster than $\mathrm{A}^{*}$ ). Yap et al. [177] also introduced another algorithm named Block $\mathrm{A}^{*}$ and compared its performance with $A^{*}$ and Theta*. Another comparative study including Accelerated $A^{*}$, Block $A^{*}$, Field-D* and Theta* was provided by Nash and Koenig [11], also including variants of the latter algorithm. The same authors later compared this algorithm with the use of visibility graphs [178]. Muñoz and R-Moreno [179] proposed the use of S-Theta* to produce paths that smooth the heading changes. 3DANA is used to produce paths on elevation maps $[180,181]$. Other algorithms that have shown improved results compared to Theta* and many other Any-angle algorithms include Any-angle Subgoal Graphs [182,183] and Anya [184,185].

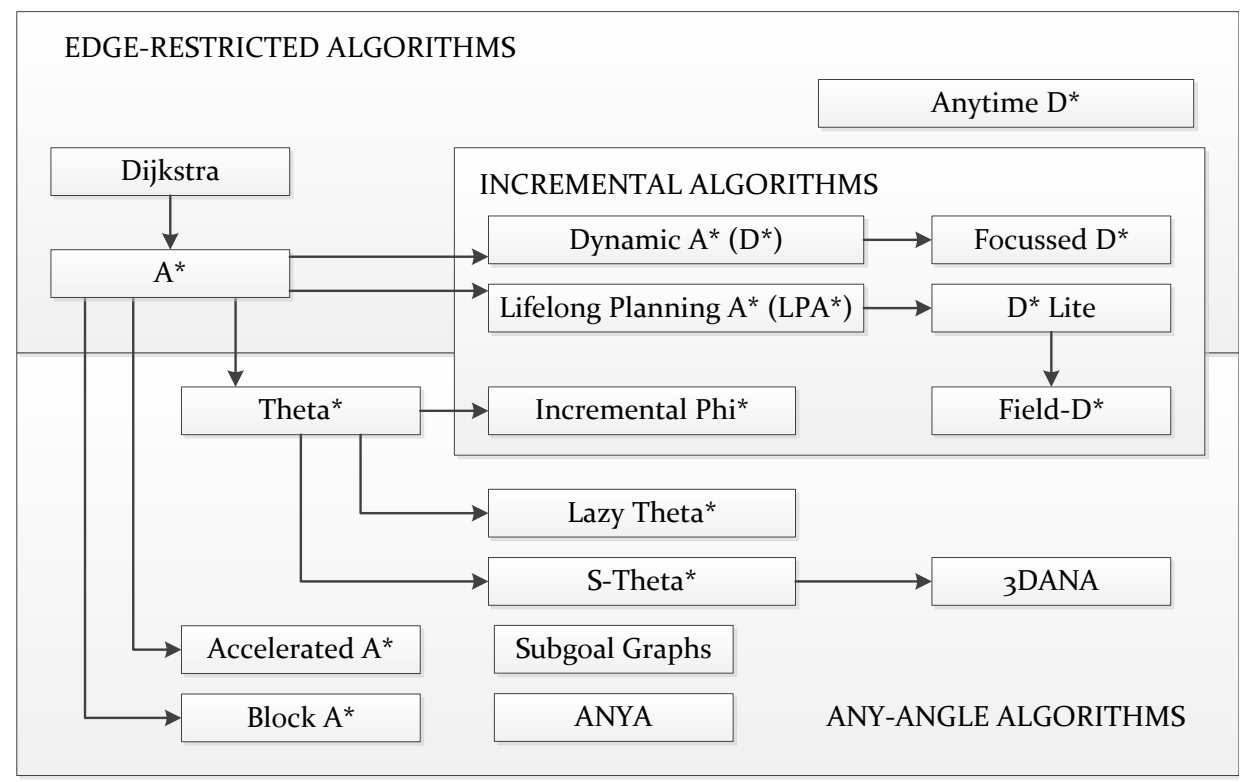

Figure 9. Overview of many different approaches to Graph Search path planning. The arrows indicate how most of them rest on older approaches yet introduce significant improvements.

\subsection{Sampling-Based}

Sampling-Based path planning algorithms create samples of the C-Space one after another, following different policies [12,186]. Later on, they retrieve the path from the created samples after meeting a certain condition or set of conditions, such as reaching a time limit. This kind of algorithm is asymptotically optimal. It means they can create more and more samples, attempting to find a better solution as time goes on. In general, these algorithms are usually used for searches in high-dimensional spaces. However, the number of samples may be relatively large in order to get close to the global optimal solution [14], demanding the use of large memory resources to store all the samples.

If only two points are considered (the starting position or state and goal), the algorithm is a single-query algorithm, whereas if more points are selected for the same environment then the algorithm is categorized as multiple-query. With regards to the single-query, one of the most famous is the Rapidly Random Tree (RRT) algorithm, which is also a special case of 
the Rapidly Deterministic Tree (RDT) [187]. This algorithm emulates a tree growing in the sense that from a starting point the samples are dynamically created as if they were branches. Figure 10a depicts an scheme summarizing this process. When one of the samples is closer to the goal than a certain distance, then the path can be retrieved by tracking backwards until reaching the origin point. As mentioned, more iterations can still be executed to find better paths. Further modifications of RRT can be found in the literature. A bi-directional version was introduced by Kuffner and LaValle [188] with the name of RRT-Connect. Later on, Yershova et al. [189] presented an improved version of RRT called Dynamic Domain RRT, which was aware of the obstacles existing in the environment during the expansion of the tree. Arslan and Tsiotras [190] took ideas from the Graph Search algorithm LPA to make RRT\#, an improved version of RRT with a faster convergence rate. Karaman and Frazzoli [186] introduced a heuristic version of RRT named Heuristic RRT (RRT*) to speed up computation while still being asymptotically optimal. For an extensive review of RRT* variants, refer to the work of Noreen et al. [14]. An improved version called Informed RRT* improved upon the performance of RRT* by delimiting an ellipse enclosing the start and goal positions when a feasible path is found [191]. The next iterations to improve this path are done within this ellipse, instead of making the algorithm explore other options that probably will not influence the result. Gammell et al. [192] presented another improvement to this, called Batch Informed Trees (BIT*), together with a comparison demonstrating its better performance than RRT*, Informed RRT* and FMT*. BIT* also takes some steps from the Graph Search algorithm LPA*. Regionally Accelerated Batch Informed Trees (AIT*) improved upon BIT*, especially for cases where narrow corridors exist [193]. The Adaptively Informed Trees (AIT*) and Advanced Batch Informed Trees (ABIT*) algorithms improved upon the BIT* algorithm and were integrated into an experimental NASA rover $[194,195]$.

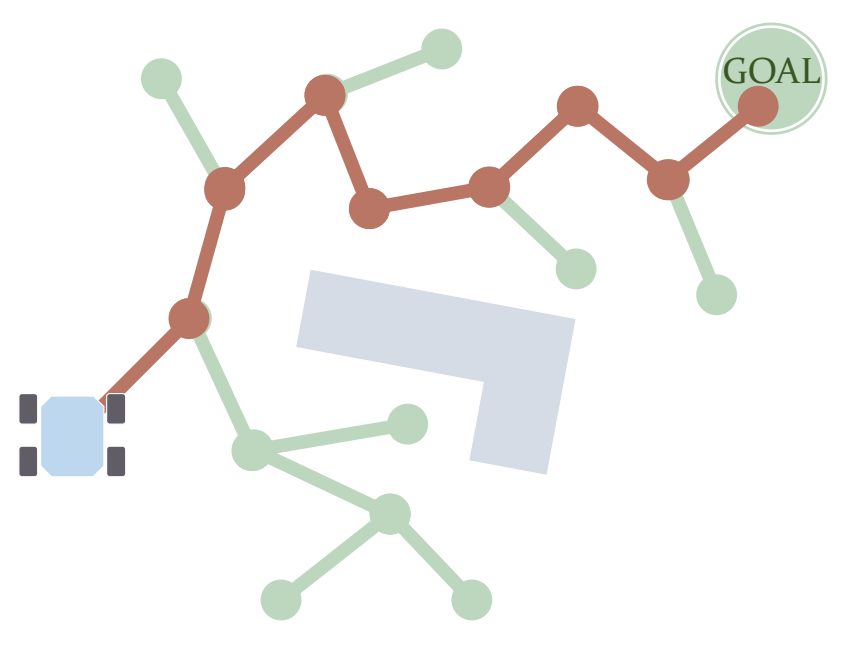

(a)

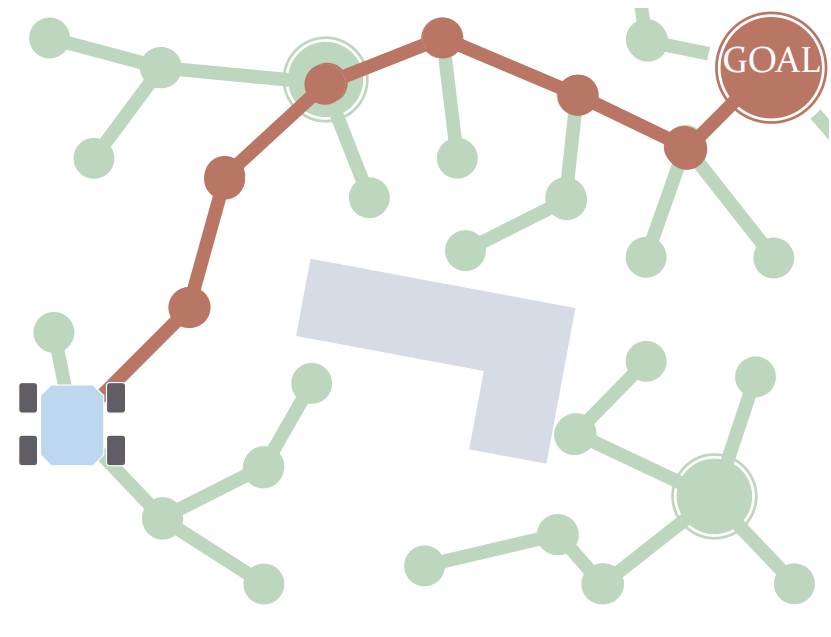

(b)

Figure 10. Example cases of single-query (a) and multiple-query (b) Sampling-Based algorithms. Samples are created in an iterative way until the destination is reached.

With regards to multiple-query Sampling-Based algorithms, the most famous is the Probabilistic Roadmap Method (PRM) [196]. This algorithm starts with a series of samples that are already scattered over the C-Space. From here, new samples are created, creating a new tree from each of these initial samples. Figure $10 \mathrm{~b}$ illustrates the concept behind this process. Thereafter, a Graph Search method such as $A^{*}$ is used to retrieve the path using the graph created by PRM. Karaman and Frazzoli [186] introduced a heuristic version of PRM. The improvement proposed by Park et al. [197] uses a hierarchical structure that reduces the number of samples. PRM has been tested in robots within simulated indoor scenarios in the work of Alenezi et al. [1]. Ichter et al. [198] presented Critical PRM, an algorithm that combines PRM with Reinforcement Learning to determine critical locations such as narrow corridors. 
Another Sampling-Based algorithm, named the Fast Marching Tree (FMT*) algorithm, was created to reduce the convergence rate of both RRT and PRM. It takes features from not only the two of them but also an Optimal Control algorithm called FMM, which is detailed below. The main objective of FMT* is to find paths, avoiding obstacles, in problems involving a high number of degrees of freedom. One example of this is the motion planning of an articulated vehicle presented by Reid et al. [50]. Ichter et al. [199] propose the use of Group Marching Tree (GMT*), a similar algorithm to FMT* but which focuses on speeding up computation via parallelization using GPUs. Finally, it is worth mentioning there are path planning algorithms that combine the Dynamic Sampling approach with Model Predictive Control (MPC) techniques to account for kinodynamic constraints $[57,200,201]$.

\section{Optimal-Control-Based Path Planning Algorithms}

The baseline of Control Approach based algorithms is the creation of a control function that takes the robot from an initial state in the C-Space to the destination. As the name suggests, here the path planning problem is addressed using an optimal control approach [202]. The main difference with Soft Computation methods is that there are no configurable parameters; the problem here must be fully enclosed. Here, there are two different subcategories. In the first of them, $P D E$ Solving, algorithms solve a Partial Derivative Equation (PDE) on a grid, based on the Dynamic Programming Principle (DPP) [203]. The second subcategory, Numerical Optimization, encompasses algorithms that in general optimize a pre-existing path given the kino-dynamic restrictions of the robot to make it feasible.

\subsection{PDE-Solving-Based}

The optimal control approach is based here on the Dynamic Programming Principle through the resolution of the Hamilton-Jacobi-Bellman equation [204] using a grid. Since it is a partial derivative equation (PDE), this sub-category is named PDE Solving. It can be seen as finding the numerical solution to the problem of calculating the propagation of a wave over a grid. A value of the wave arrival time is assigned to each of the grid nodes. The way the wave propagates will depend on how the HJB equation is formulated, including the cost function. The main drawback of this kind of algorithm is that it generally cannot deal with constraints in the form of discontinuities.

A particular case of the HJB equation is the Eikonal equation. This is not only static but also considers the cost function and only returns a scalar value according to the position on the map. This means the wave propagates on a node with a rate that depends only on the assigned scalar value. In this way, the characteristic directions are coincident with the gradient of the Total Cost function, and hence the path can be retrieved simply using a Gradient Descent method. A whole family of methods have been proposed over the years to compute the solution to this problem-formulation with low computational requirements, and hence they are named Fast methods [18]. One of the most well-known is the Fast Marching Method (FMM), introduced by Sethian [205]. This algorithm follows the same strategy as Dijkstra to visit the nodes of a grid. Unlike Dijkstra, FMM assigns the value of an amount of cost to each node by solving the Eikonal algorithm. The resulting path is smooth, continuous and optimal. Chiang et al. [206] compared this algorithm with $\mathrm{A}^{*}$ and demonstrated how, as the path is not restricted by the grid, FMM gets shorter paths. There are many existing works using FMM for path planning [207-210]. Some of its variants, most of them reducing the computational power requirements of FMM, are introduced in the review by Gómez et al. [18], along with other Eikonal solvers. They are Binary FMM, Fibonacci FMM, Simplified FMM and Untidy FMM. The cost values used by the Eikonal determine the rate of propagation of the computed wave. Petres et al. [24] demonstrated how the gradient of these cost values affects the curvature radius of the resulting path. Their work also introduced the idea of Heuristic Fast Marching $\left(\mathrm{FM}^{*}\right)$ and also compares this with other Graph Search algorithms. For smooth obstacle avoidance, Fast Marching Square (FMS) [74] computes FMM twice, being the first to create a repulsive field surrounding obstacles. Figure 11a depicts how the path smoothly gets further from the 
obstacle thanks to the higher values of cost near it (darker colors). Liu and Bucknall [211] used FMS, along with a modification of the cost around the initial position, to consider the initial orientation of the vehicle. Researchers have also aimed to propose incremental versions of FMM, such as $E^{*}[212-214]$.

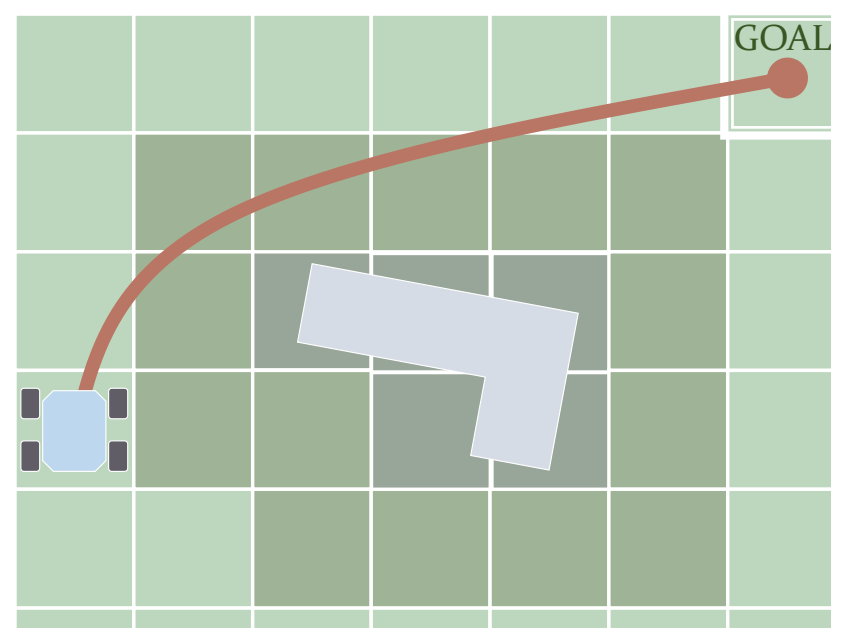

(a)

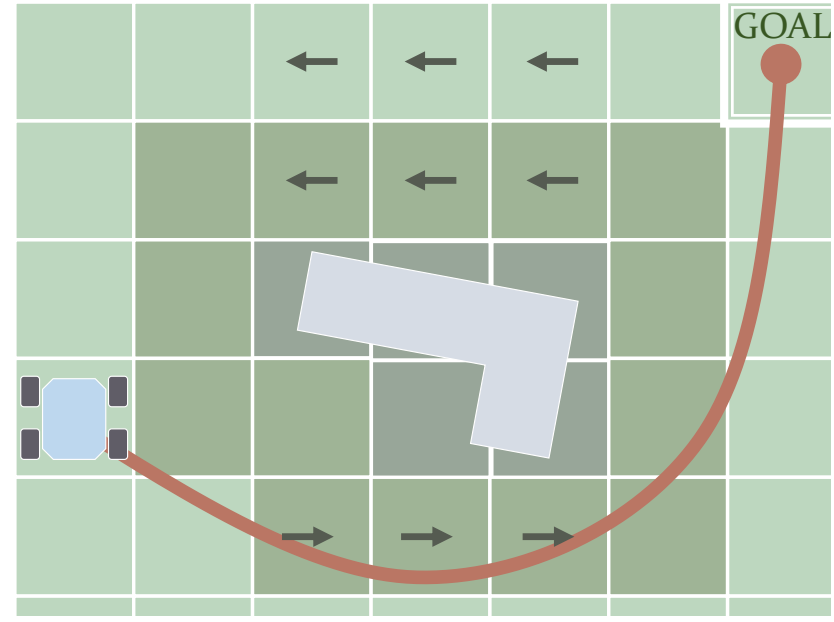

(b)

Figure 11. PDE-Solving-based algorithms can calculate a continuous and smooth path in non-uniform cost maps. The cost assigned to each cell can be a scalar value or isotropic (a) or in the form of a vector, i.e., anisotropic (b).

To work with more general expressions of the Hamilton-Jacobi-0Bellman (HJB) equation, other kinds of methods must be used. FMM produces sub-optimal results if used with direction-dependent (anisotropic) costs [215]. This kind of cost implies that the wave propagates differently depending on its direction relative to how a vectorial cost is assigned to the node. There are particular situations in which FMM produces accurate results under a certain level of anisotropy, such as having a cost function formulated in such a way thatit varies mostly in the directions parallel to the reference axes $[24,216]$. This is the case depicted in Figure 11b. Sethian and Vladimirsky [215] proposed the use of an algorithm called the Ordered Upwind Method (OUM) to deal with the static HJB equation, the convergence rate of which was demonstrated by Shum et al. [217]. Its main drawback is the increase in computational cost it entails, proportional to the anisotropy existing in the scenario. Shum et al. [31] used HJB for anisotropic path planning, considering energy minimization and stability, and considering the direction and magnitude of slopes. The Fast Sweeping Method (FSM) has also been demonstrated to work with general static HJB equations [218]. It works by visiting all nodes on a grid, following certain directions repeatedly, which means that it demands a high number of iterations. Takei and Tsai [37] used FSM to formulate the HJB equation to comply with turning radius constraints. For the Eikonal case, Bak et al. [219] introduced an improvement to FSM to speed up its computation when the cost varies too much, and Detrixhe et al. [220] introduced a parallel version. Jeong and Whitaker [221] proposed an algorithm named the Fast Iterative Method (FIM) to solve the Eikonal equation on parallel architectures as well.

\subsection{Global Optimization}

This subcategory contains path planning algorithms that optimize an existing preliminary feasible path. Unlike Local Optimization methods, introduced in Section 3.1, Global Optimization methods make the resulting path globally optimal in exchange for investing more of a computational load. The approach presented by Ratliff et al. [222], for instance, uses Sampling-Based methods such as RRT or PRM as a first step. The second step consists of using gradient optimization techniques to approximate the optimal solution from this feasible path. Van Den Berg et al. [223] also started with a trajectory computed using RRT, to later apply jt to an optimization process based on Differential Dynamic Program- 
ming (DP). Plonski et al. [70] used DP to calculate a path in a solar map that dynamically changes, considering that the robot harvests solar energy. Ajanović et al. [224] combined DP with Model Predictive Control (MPC) to calculate energy-minimizing paths. Other techniques include the bang-bang approach [225] and Mixed-Integer Linear Programming (MILP) [226]. Finally, a remarkable approach was proposed by Kogan and Murray [227], who used nonlinear optimization to plan time-optimal paths with a length between 20 and $70 \mathrm{~m}$.

\section{Summary and Conclusions}

Table 3 summarizes the main features of each path planning category according to the classification system proposed in this paper (see Figure 1). It analyzes whether the algorithms require a preliminary model of the environment, whether they are deterministic (i.e., they always provide the same solution given the same initial conditions), whether they can tackle dynamic environments and replan, whether they are optimal and if they are complete (i.e., they always return a path if it is feasible). Given the scope of the final path planning application, some algorithms will be more suitable than others. Moreover, the reach of the planner and the replanning capability, i.e., the capability to deal with updates in the environment information, will determine if an algorithm is more suitable for local planning or global planning. Local planning usually requires fast online computation and this reactivity behavior is required to plan new paths in the presence of environmental data changes. Global planning can even be computed offline and aims to generate paths for long traverses, having a static initial environment available.

Table 3. Overview of characteristics of the presented path planning algorithms.

\begin{tabular}{|c|c|c|c|c|c|c|}
\hline Category & Sub-Category & $\begin{array}{l}\text { Preliminary } \\
\text { Map Model }\end{array}$ & Deterministic & Replanning & Optimality & Completeness \\
\hline \multirow{2}{*}{$\begin{array}{l}\text { Reactive } \\
\text { Computing }\end{array}$} & \multirow{2}{*}{$\begin{array}{l}\text { Reactive } \\
\text { Manoeuvre } \\
\text { Local } \\
\text { Optimization }\end{array}$} & No [7] & Yes & Yes & Sub-optimal & Not ensured \\
\hline & & $\begin{array}{l}\text { Depends on planner } \\
\text { used in first step }\end{array}$ & Yes & Yes & Sub-optimal & Not ensured \\
\hline \multirow{2}{*}{$\begin{array}{l}\text { Soft } \\
\text { Computing }\end{array}$} & Evolutionary & Only ACO & No & Yes [3] & Heuristic & $\begin{array}{l}\text { Depends (e.g., GA } \\
\text { no; PSO, yes) [20] }\end{array}$ \\
\hline & $\begin{array}{l}\text { Artificial } \\
\text { Intelligence }\end{array}$ & Depends & No & Yes & Heuristic & Not ensured \\
\hline \multirow{2}{*}{$\begin{array}{l}\text { C-Space } \\
\text { Search }\end{array}$} & Graph Search & Yes $[7,11]$ & Yes [7] & Only incremental & $\begin{array}{c}\text { Global restricted } \\
\text { to graph }\end{array}$ & Yes \\
\hline & Sampling-Based & No & No [7] & Yes & Asymptotical & Probabilistic \\
\hline \multirow{2}{*}{$\begin{array}{l}\text { Optimal } \\
\text { Control }\end{array}$} & PDE Solving & Yes & Yes & Very rare [212-214] & Globally optimal & Yes \\
\hline & $\begin{array}{l}\text { Global } \\
\text { Optimization }\end{array}$ & $\begin{array}{l}\text { Depend on planner } \\
\text { used in first step }\end{array}$ & Yes & Yes [3] & Globally optimal & No [20] \\
\hline
\end{tabular}

Reactive-Computing-based algorithms seem suitable for local obstacle avoidance path planning as they are easy and cheap to implement. Furthermore, Reactive Manoeuvre methods are a good option for scenarios with high uncertainty or when using a robot with very limited sensing options. Local Optimization allows one to even consider kinodynamic constraints with TEB, although they do not ensure completeness. Special attention must be given to both subcategories, in order to avoid falling into a local minimum. Soft Computing algorithms produce a path using multiple configurable operators, which can be inspired by nature or can be based on fuzzy rules and/or neural networks. They are suitable for problems involving a large number of variables or problems that are difficult to model, such as in highly dynamic environments. With scenarios containing moving elements, in long-range (global path planning) scenarios, the use of Evolutionary methods is adequate. The latest Artificial Intelligence methods, including the DL and RL methods, still need to be further studied to obtain solid conclusions, as also remarked by Sun et al. [21]. Artificial Intelligence methods based on Fuzzy rules or neural networks can be used for fast Local 
Planning as an alternative to Reactive Manoeuvre methods. C-Space Search algorithms make use of samples to represent the different configurations of the robot. These samples can be provided beforehand in the form of a graph or they can be dynamically created. Graph Search algorithms are suitable for global path planning considering advanced graphs such as visibility graphs or space-lattice graphs, at the expense of investing time into building them (something that is admissible for offline planning). Nevertheless, it scales poorly with problems of high dimensions, which justifies the use of Sampling-based algorithms instead. Sampling-based algorithms have also proved useful for this kind of manoeuvre and problems with a high number of dimensions. Optimal Control algorithms are outstanding for obtaining globally optimal results. $P D E$-Solving-based algorithms depend heavily on the formulated PDE, which can be based on isotropic or anisotropic cost functions and can work with a map model in the form of a grid. Global Optimization algorithms have to start with an already-defined path an adapt it according to the robot's locomotion restrictions. $P D E$ Solving algorithms are adequate for the off-line computation of long traverses given low-uncertain static scenarios, as they provide optimal paths without relying on replanning. Finally, it is important to note that all these planners rely on the available information describing the environment and the robot. This information must be modeled as accurately as possible to improve the results of the path planner.

Author Contributions: Conceptualization, J.R.S.-I. and C.J.P.-d.-P.; methodology, J.R.S.-I.; investigation, J.R.S.-I.; writing—original draft preparation, J.R.S.-I.; writing—review and editing, J.R.S.-I. and C.J.P.-d.-P.; supervision, C.J.P.-d.-P. and A.G.-C.; project administration, C.J.P.-d.-P. and A.G.-C.; funding acquisition, C.J.P.-d.-P. and A.G.-C. All authors have read and agreed to the published version of the manuscript.

Funding: This research was funded by the H2020 European project: Autonomous decision-making in very long traverses, under grant agreement: 821988 , and the Andalusian regional government, Spain, under grant reference P18-RT-991.

Institutional Review Board Statement: Not applicable.

Informed Consent Statement: Not applicable.

Data Availability Statement: Not applicable.

Acknowledgments: We would like to thank Mickael Laine, from the University of Tohoku, and Florian Cordes, from DFKI, for giving us permission to reproduce the images shown in Figure 3a,c respectively. We would like to thank M.A. Annemarie Popp, from DFKI, for taking the photo image in Figure 3c.

Conflicts of Interest: The authors declare no conflict of interest.

\author{
Abbreviations

$\begin{array}{ll}\text { ACO } & \text { Ant Colony Optimizer } \\ \text { AIT* } & \text { Adaptively Informed Tree } \\ \text { APF } & \text { Artificial Potential Fields } \\ \text { ABIT }^{*} & \text { Advanced Batch Informed Trees } \\ \text { BIT }^{*} & \text { Batch Informed Trees } \\ \text { D }^{*} & \text { Dynamic A* } \\ \text { DEM } & \text { Digital Elevation Map } \\ \text { DL } & \text { Deep Learning } \\ \text { DP } & \text { Dynamic Programming } \\ \text { DPP } & \text { Dynamic Programming Principle } \\ \text { DWA } & \text { Dynamic Window Approach } \\ \text { FIM } & \text { Fast Iterative Method } \\ \text { FMM } & \text { Fast Marching Method } \\ \text { FMT } & \text { Fast Marching Tree } \\ \text { FMS } & \text { Fast Marching Square }\end{array}$

The following abbreviations are used in this manuscript: 


$\begin{array}{ll}\text { FSM } & \text { Fast Sweeping Method } \\ \text { FM* }^{*} & \text { Heuristic Fast Marching } \\ \text { GMT }^{*} & \text { Group Marching Tree } \\ \text { HJB } & \text { Hamilton-Jacobi-Bellman } \\ \text { LPA }^{*} & \text { Lifelong Planning A* } \\ \text { MPC } & \text { Model Predictive Control } \\ \text { OUM } & \text { Ordered Upwind Method } \\ \text { PDE } & \text { Partial Derivative Equation } \\ \text { PRM } & \text { Probabilistic Roadmap Method } \\ \text { PSO } & \text { Particle Swarm Optimizer } \\ \text { RABIT* } & \text { Regionally Accelerated Batch Informed Trees } \\ \text { RDT } & \text { Rapidly Deterministic Tree } \\ \text { RL } & \text { Reinforcement Learning } \\ \text { RRT } & \text { Rapidly Random Tree } \\ \text { RRT } & \text { Heuristic Rapidly Random Tree } \\ \text { TEB } & \text { Timed Elastic Bands } \\ \text { VFH } & \text { Vector Field Histogram }\end{array}$

\section{References}

1. Alenezi, M.R.; Almeshal, A.M. Optimal Path Planning for a Remote Sensing Unmanned Ground Vehicle in a Hazardous Indoor Environment. Intell. Control Autom. 2018, 9, 88507. [CrossRef]

2. Ishigami, G.; Nagatani, K.; Yoshida, K. Path planning and evaluation for planetary rovers based on dynamic mobility index. In Proceedings of the 2011 IEEE/RSJ International Conference on Intelligent Robots and Systems, San Francisco, CA, USA, 25-30 September 2011; pp. 601-606.

3. Raja, P.; Pugazhenthi, S. Optimal path planning of mobile robots: A review. Int. J. Phys. Sci. 2012, 7, 1314-1320. [CrossRef]

4. Zhang, H.Y.; Lin, W.M.; Chen, A.X. Path planning for the mobile robot: A review. Symmetry 2018, 10, 450. [CrossRef]

5. Zhang, F.; Li, N.; Xue, T.; Zhu, Y.; Yuan, R.; Fu, Y. An Improved Dynamic Window Approach Integrated Global Path Planning. In Proceedings of the 2019 IEEE International Conference on Robotics and Biomimetics (ROBIO), Dali, China, 6-8 December 2019; pp. 2873-2878.

6. Vagale, A.; Oucheikh, R.; Bye, R.T.; Osen, O.L.; Fossen, T.I. Path planning and collision avoidance for autonomous surface vehicles I: A review. J. Mar. Sci. Technol. 2021, 26, 1292-1306. [CrossRef]

7. Souissi, O.; Benatitallah, R.; Duvivier, D.; Artiba, A.; Belanger, N.; Feyzeau, P. Path planning: A 2013 survey. In Proceedings of the 2013 International Conference on Industrial Engineering and Systems Management (IESM), Rabat, Morocco, 28-30 October 2013; pp. 1-8.

8. Mac, T.T.; Copot, C.; Tran, D.T.; De Keyser, R. Heuristic approaches in robot path planning: A survey. Robot. Auton. Syst. 2016, 86, 13-28. [CrossRef]

9. Zafar, M.N.; Mohanta, J. Methodology for path planning and optimization of mobile robots: A review. Procedia Comput. Sci. 2018, 133, 141-152. [CrossRef]

10. Patle, B.; Pandey, A.; Parhi, D.; Jagadeesh, A. A review: On path planning strategies for navigation of mobile robot. Def. Technol. 2019, 15, 582-606. [CrossRef]

11. Nash, A.; Koenig, S. Any-angle path planning. AI Mag. 2013, 34, 85-107. [CrossRef]

12. Elbanhawi, M.; Simic, M. Sampling-based robot motion planning: A review. IEEE Access 2014, 2, 56-77. [CrossRef]

13. González, D.; Pérez, J.; Milanés, V.; Nashashibi, F. A review of motion planning techniques for automated vehicles. IEEE Trans. Intell. Transp. Syst. 2015, 17, 1135-1145. [CrossRef]

14. Noreen, I.; Khan, A.; Habib, Z. Optimal path planning using RRT* based approaches: A survey and future directions. Int. J. Adv. Comput. Sci. Appl. 2016, 7, 97-107. [CrossRef]

15. Injarapu, A.S.H.H.V.; Gawre, S.K. A survey of autonomous mobile robot path planning approaches. In Proceedings of the 2017 International Conference on Recent Innovations in Signal Processing and Embedded Systems (RISE), Bhopal, India, 27-29 October 2017; pp. 624-628.

16. Ravankar, A.; Ravankar, A.A.; Kobayashi, Y.; Hoshino, Y.; Peng, C.C. Path smoothing techniques in robot navigation: State-of-theart, current and future challenges. Sensors 2018, 18, 3170. [CrossRef]

17. Costa, M.M.; Silva, M.F. A survey on path planning algorithms for mobile robots. In Proceedings of the 2019 IEEE International Conference on Autonomous Robot Systems and Competitions (ICARSC), Cosme, Portugal, 24-26 April 2019; pp. 1-7.

18. Gómez, J.V.; Álvarez, D.; Garrido, S.; Moreno, L. Fast methods for eikonal equations: An experimental survey. IEEE Access 2019, 7, 39005-39029. [CrossRef]

19. Campbell, S.; O’Mahony, N.; Carvalho, A.; Krpalkova, L.; Riordan, D.; Walsh, J. Path planning techniques for mobile robots a review. In Proceedings of the 2020 6th International Conference on Mechatronics and Robotics Engineering (ICMRE), Barcelona, Spain, 12-15 February 2020; pp. 12-16. 
20. Zhang, H.; Zhang, Y.; Yang, T. A survey of energy-efficient motion planning for wheeled mobile robots. Ind. Robot. Int. J. Robot. Res. Appl. 2020, 47, 607-621. [CrossRef]

21. Sun, H.; Zhang, W.; Runxiang, Y.; Zhang, Y. Motion planning for mobile Robots-focusing on deep reinforcement learning: A systematic Review. IEEE Access 2021, 9, 69061-69081. [CrossRef]

22. Yi, C.; Jeong, S.; Cho, J. Map representation for robots. Smart Comput. Rev. 2012, 2, 18-27. [CrossRef]

23. Algfoor, Z.A.; Sunar, M.S.; Kolivand, H. A comprehensive study on pathfinding techniques for robotics and video games. Int. J. Comput. Games Technol. 2015, 2015, 7. [CrossRef]

24. Petres, C.; Pailhas, Y.; Petillot, Y.; Lane, D. Underwater path planing using fast marching algorithms. In Proceedings of the Oceans 2005-Europe, Brest, France, 20-23 June 2005; Volume 2, pp. 814-819.

25. Barraquand, J.; Langlois, B.; Latombe, J.C. Numerical potential field techniques for robot path planning. IEEE Trans. Syst. Man Cybern. 1992, 22, 224-241. [CrossRef]

26. Huang, H.P.; Chung, S.Y. Dynamic visibility graph for path planning. In Proceedings of the 2004 IEEE/RSJ International Conference on Intelligent Robots and Systems (IROS) (IEEE Cat. No. 04CH37566), Sendai, Japan, 28 September-2 October 2004; Volume 3, pp. 2813-2818.

27. Likhachev, M.; Ferguson, D. Planning long dynamically feasible maneuvers for autonomous vehicles. Int. J. Robot. Res. 2009, 28, 933-945. [CrossRef]

28. Bergman, K.; Ljungqvist, O.; Axehill, D. Improved path planning by tightly combining lattice-based path planning and optimal control. IEEE Trans. Intell. Veh. 2020, 6, 57-66. [CrossRef]

29. Choi, S.; Park, J.; Lim, E.; Yu, W. Global path planning on uneven elevation maps. In Proceedings of the 2012 9th International Conference on Ubiquitous Robots and Ambient Intelligence (URAI), Daejeon, Korea, 26-28 November 2012; pp. 49-54.

30. Papadakis, P. Terrain traversability analysis methods for unmanned ground vehicles: A survey. Eng. Appl. Artif. Intell. 2013, 26, 1373-1385. [CrossRef]

31. Shum, A.; Morris, K.; Khajepour, A. Direction-dependent optimal path planning for autonomous vehicles. Robot. Auton. Syst. 2015, 70, 202-214. [CrossRef]

32. Papadopoulos, E.; Misailidis, M. On differential drive robot odometry with application to path planning. In Proceedings of the 2007 European Control Conference (ECC), Kos, Greece, 2-5 July 2007; pp. 5492-5499.

33. Laîné, M.; Tamakoshi, C.; Touboulic, M.; Walker, J.; Yoshida, K. Initial design characteristics, testing and performance optimisation for a lunar exploration micro-rover prototype. Adv. Astronaut. Sci. Technol. 2018, 1, 111-117. [CrossRef]

34. Marin, L.; Vallés, M.; Soriano, A.; Valera, A.; Albertos, P. Event-based localization in ackermann steering limited resource mobile robots. IEEE/ASME Trans. Mechatron. 2013, 19, 1171-1182. [CrossRef]

35. Mandow, A.; Martinez, J.L.; Morales, J.; Blanco, J.L.; Garcia-Cerezo, A.; Gonzalez, J. Experimental kinematics for wheeled skid-steer mobile robots. In Proceedings of the 2007 IEEE/RSJ International Conference on Intelligent Robots and Systems, San Diego, CA, USA, 29 October-2 November 2007; pp. 1222-1227.

36. Wu, M.; Dai, S.L.; Yang, C. Mixed reality enhanced user interactive path planning for omnidirectional mobile robot. Appl. Sci. 2020, 10, 1135. [CrossRef]

37. Takei, R.; Tsai, R. Optimal trajectories of curvature constrained motion in the hamilton-jacobi formulation. J. Sci. Comput. 2013, 54, 622-644. [CrossRef]

38. Effati, M.; Fiset, J.S.; Skonieczny, K. Considering slip-track for energy-efficient paths of skid-steer rovers. J. Intell. Robot. Syst. 2020, 100, 335-348. [CrossRef]

39. Patel, N.; Slade, R.; Clemmet, J. The ExoMars rover locomotion subsystem. J. Terramech. 2010, 47, 227-242. [CrossRef]

40. Rohmer, E.; Yoshida, T.; Ohno, K.; Nagatani, K.; Tadokoro, S.; Konayagi, E. Quince: A collaborative mobile robotic platform for rescue robots research and development. In The Abstracts of the International Conference on Advanced Mechatronics: Toward Evolutionary Fusion of IT and Mechatronics: ICAM 2010.5; The Japan Society of Mechanical Engineers: Tokyo, Japan, 2010; pp. 225-230.

41. Brunner, M.; Fiolka, T.; Schulz, D.; Schlick, C.M. Design and comparative evaluation of an iterative contact point estimation method for static stability estimation of mobile actively reconfigurable robots. Robot. Auton. Syst. 2015, 63, 89-107. [CrossRef]

42. Azkarate, M.; Zwick, M.; Hidalgo-Carrio, J.; Nelen, R.; Wiese, T.; Poulakis, P.; Joudrier, L.; Visentin, G. First Experimental investigations on Wheel-Walking for improving Triple-Bogie rover locomotion performances. In Proceedings of the 13th Symposium on Advanced Space Technologies in Robotics and Automation, Noordwijk, The Netherlands, 11-13 May 2015; pp. 1-6.

43. Malenkov, M.; Volov, V. Wheel-walking propulsion unit of a planetary rover with active suspension. Russ. Eng. Res. 2017, 37, 1033-1040. [CrossRef]

44. Moreland, S.; Skonieczny, K.; Wettergreen, D.; Asnani, V.; Creager, C.; Oravec, H. Inching locomotion for planetary rover mobility. In Proceedings of the 2011 IEEE Aerospace Conference, Big Sky, MT, USA, 5-12 March 2011; pp. 1-6.

45. Creager, C.; Moreland, S.; Skonieczny, K.; Johnson, K.; Asnani, V.; Gilligan, R. Benefit of "Push-Pull" Locomotion for Planetary Rover Mobility. In Proceedings of the Thirteenth ASCE Aerospace Division Conference on Engineering, Science, Construction, and Operations in Challenging Environments, and the 5th NASA/ASCE Workshop On Granular Materials in Space Exploration, Pasadena, CA, USA, 15-18 April 2012; American Society of Civil Engineers: Reston, VA, USA, 2012; pp. 11-20. 
46. Creager, C.; Johnson, K.; Plant, M.; Moreland, S.; Skonieczny, K. Push-pull locomotion for vehicle extrication. J. Terramech. 2015, 57, 71-80. [CrossRef]

47. Rohmer, E.; Reina, G.; Yoshida, K. Dynamic Simulation-Based Action Planner for a Reconfigurable Hybrid Leg-Wheel Planetary Exploration Rover. Adv. Robot. 2010, 24, 1219-1238. [CrossRef]

48. Pérez-del Pulgar, C.J.; Sánchez, J.; Sánchez, A.; Azkarate, M.; Visentin, G. Path planning for reconfigurable rovers in planetary exploration. In Proceedings of the 2017 IEEE International Conference on Advanced Intelligent Mechatronics (AIM), Munich, Germany, 3-7 July 2017; pp. 1453-1458.

49. Sánchez-Ibánez, J.R.; Pérez-del Pulgar, C.J.; Azkarate, M.; Gerdes, L.; García-Cerezo, A. Dynamic path planning for reconfigurable rovers using a multi-layered grid. Eng. Appl. Artif. Intell. 2019, 86, 32-42. [CrossRef]

50. Reid, W.; Fitch, R.; Göktoğan, A.H.; Sukkarieh, S. Sampling-based hierarchical motion planning for a reconfigurable wheel-on-leg planetary analogue exploration rover. J. Field Robot. 2019, 37, 786-811. [CrossRef]

51. Weih Jr, R.C.; Mattson, T.L. Modeling slope in a geographic information system. J. Ark. Acad. Sci. 2004, 58, 100-108.

52. Miró, J.V.; Dumonteil, G.; Beck, C.; Dissanayake, G. A kyno-dynamic metric to plan stable paths over uneven terrain. In Proceedings of the 2010 IEEE/RSJ International Conference on Intelligent Robots and Systems, Taipei, Taiwan, 18-22 October 2010; pp. 294-299.

53. Norouzi, M.; Miro, J.V.; Dissanayake, G. Planning stable and efficient paths for reconfigurable robots on uneven terrain. J. Intell. Robot. Syst. 2017, 87, 291-312. [CrossRef]

54. Rowe, N.C.; Ross, R.S. Optimal grid-free path planning across arbitrarily-contoured terrain with anisotropic friction and gravity effects. IEEE Trans. Robot. Autom. 1990, 6, 540-553. [CrossRef]

55. Ganganath, N.; Cheng, C.T.; Chi, K.T. A constraint-aware heuristic path planner for finding energy-efficient paths on uneven terrains. IEEE Trans. Ind. Inform. 2015, 11, 601-611. [CrossRef]

56. Ganganath, N.; Cheng, C.T.; Fernando, T.; Iu, H.H.; Chi, K.T. Shortest path planning for energy-constrained mobile platforms navigating on uneven terrains. IEEE Trans. Ind. Inform. 2018, 14, 4264-4272. [CrossRef]

57. Gruning, V.; Pentzer, J.; Brennan, S.; Reichard, K. Energy-Aware Path Planning for Skid-Steer Robots Operating on Hilly Terrain. In Proceedings of the 2020 American Control Conference (ACC), Denver, CO, USA, 1-3 July 2020; pp. 2094-2099.

58. Krüsi, P.; Furgale, P.; Bosse, M.; Siegwart, R. Driving on point clouds: Motion planning, trajectory optimization, and terrain assessment in generic nonplanar environments. J. Field Robot. 2017, 34, 940-984. [CrossRef]

59. Lindsay, J.B.; Newman, D.R.; Francioni, A. Scale-Optimized Surface Roughness for Topographic Analysis. Geosciences 2019, 9, 322. [CrossRef]

60. Raghavan, V.S.; Kanoulas, D.; Laurenzi, A.; Caldwell, D.G.; Tsagarakis, N.G. Variable configuration planner for legged-rolling obstacle negotiation locomotion: Application on the centauro robot. In Proceedings of the 2019 IEEE/RSJ International Conference on Intelligent Robots and Systems (IROS), Macau, China, 4-8 November 2019; pp. 4738-4745.

61. Otsu, K.; Matheron, G.; Ghosh, S.; Toupet, O.; Ono, M. Fast approximate clearance evaluation for rovers with articulated suspension systems. J. Field Robot. 2020, 37, 768-785. [CrossRef]

62. Hines, T.; Stepanas, K.; Talbot, F.; Sa, I.; Lewis, J.; Hernandez, E.; Kottege, N.; Hudson, N. Virtual Surfaces and Attitude Aware Planning and Behaviours for Negative Obstacle Navigation. IEEE Robot. Autom. Lett. 2021, 6, 4048-4055. [CrossRef]

63. Taghavifar, H.; Rakheja, S.; Reina, G. A novel optimal path-planning and following algorithm for wheeled robots on deformable terrains. J. Terramech. 2020, 96, 147-157. [CrossRef]

64. Arvidson, R.E.; Bell, J.; Bellutta, P.; Cabrol, N.A.; Catalano, J.; Cohen, J.; Crumpler, L.S.; Des Marais, D.; Estlin, T.; Farrand, W.; et al. Spirit Mars Rover Mission: Overview and selected results from the northern Home Plate Winter Haven to the side of Scamander crater. J. Geophys. Res. Planets 2010, 115, 1-19. [CrossRef]

65. Ishigami, G.; Nagatani, K.; Yoshida, K. Path planning for planetary exploration rovers and its evaluation based on wheel slip dynamics. In Proceedings of the 2007 IEEE International Conference on Robotics and Automation, Rome, Italy, 10-14 April 2007; pp. 2361-2366.

66. Sutoh, M.; Otsuki, M.; Wakabayashi, S.; Hoshino, T.; Hashimoto, T. The right path: Comprehensive path planning for lunar exploration rovers. IEEE Robot. Autom. Mag. 2015, 22, 22-33. [CrossRef]

67. Inotsume, H.; Creager, C.; Wettergreen, D.; Whittaker, W. Finding routes for efficient and successful slope ascent for exploration rovers. In Proceedings of the 13th International Symposium on Artificial Intelligence, Robotics and Automation in Space (i-SAIRAS), Beijing, China, 19-22 June 2016; pp. 1-10.

68. Inotsume, H.; Kubota, T.; Wettergreen, D. Robust Path Planning for Slope Traversing under Uncertainty in Slip Prediction. IEEE Robot. Autom. Lett. 2020, 5, 3390-3397. [CrossRef]

69. Niksirat, P.; Daca, A.; Skonieczny, K. The effects of reduced-gravity on planetary rover mobility. Int. J. Robot. Res. 2020, 39, 797-811. [CrossRef]

70. Plonski, P.A.; Tokekar, P.; Isler, V. Energy-efficient path planning for solar-powered mobile robots. J. Field Robot. 2013, 30, 583-601. [CrossRef]

71. Kaplan, A.; Kingry, N.; Uhing, P.; Dai, R. Time-optimal path planning with power schedules for a solar-powered ground robot. IEEE Trans. Autom. Sci. Eng. 2016, 14, 1235-1244. [CrossRef]

72. Groves, K.; Hernandez, E.; West, A.; Wright, T.; Lennox, B. Robotic Exploration of an Unknown Nuclear Environment Using Radiation Informed Autonomous Navigation. Robotics 2021, 10, 78. [CrossRef] 
73. Ono, M.; Fuchs, T.J.; Steffy, A.; Maimone, M.; Yen, J. Risk-aware planetary rover operation: Autonomous terrain classification and path planning. In Proceedings of the 2015 IEEE Aerospace Conference, Big Sky, MT, USA, 7-14 March 2015; pp. 1-10.

74. Valero-Gomez, A.; Gomez, J.V.; Garrido, S.; Moreno, L. The path to efficiency: Fast marching method for safer, more efficient mobile robot trajectories. IEEE Robot. Autom. Mag. 2013, 20, 111-120. [CrossRef]

75. Khatib, O. Real-time obstacle avoidance for manipulators and mobile robots. In Proceedings of the 1985 IEEE International Conference on Robotics and Automation, St. Louis, MO, USA, 25-28 March 2015; Volume 2, pp. 500-505.

76. Ge, S.S.; Cui, Y.J. Dynamic motion planning for mobile robots using potential field method. Auton. Robot. 2002, 13, 207-222. [CrossRef]

77. Vadakkepat, P.; Tan, K.C.; Ming-Liang, W. Evolutionary artificial potential fields and their application in real time robot path planning. In Proceedings of the 2000 Congress on Evolutionary Computation, CEC00 (Cat. No. 00TH8512), La Jolla, CA, USA, 16-19 July 2000; Volume 1, pp. 256-263.

78. Raja, R.; Dutta, A.; Venkatesh, K. New potential field method for rough terrain path planning using genetic algorithm for a 6-wheel rover. Robot. Auton. Syst. 2015, 72, 295-306. [CrossRef]

79. Zhou, Z.; Wang, J.; Zhu, Z.; Yang, D.; Wu, J. Tangent navigated robot path planning strategy using particle swarm optimized artificial potential field. Optik 2018, 158, 639-651. [CrossRef]

80. Triharminto, H.; Wahyunggoro, O.; Adji, T.; Cahyadi, A.; Ardiyanto, I. A novel of repulsive function on artificial potential field for robot path planning. Int. J. Electr. Comput. Eng. 2016, 6, 3262.

81. Kim, D.H. Escaping route method for a trap situation in local path planning. Int. J. Control Autom. Syst. 2009, 7, 495-500. [CrossRef]

82. Bayat, F.; Najafinia, S.; Aliyari, M. Mobile robots path planning: Electrostatic potential field approach. Expert Syst. Appl. 2018, 100, 68-78. [CrossRef]

83. Borenstein, J.; Koren, Y. The vector field histogram-fast obstacle avoidance for mobile robots. IEEE Trans. Robot. Autom. 1991, 7, 278-288. [CrossRef]

84. Ulrich, I.; Borenstein, J. VFH+: Reliable obstacle avoidance for fast mobile robots. In Proceedings of the 1998 IEEE International Conference on Robotics and Automation (Cat. No. 98CH36146), Leuven, Belgium, 16-20 May 1998; Volume 2, pp. $1572-1577$.

85. Ulrich, I.; Borenstein, J. VFH*: Local Obstacle Avoidance with Lookahead Verification. In Proceedings of the 2000 IEEE International Conference on Robotics and Automation (ICRA 2000), San Francisco, CA, USA, 24-28 April 2000.

86. Lumelsky, V.; Stepanov, A. Dynamic path planning for a mobile automaton with limited information on the environment. IEEE Trans. Autom. Control 1986, 31, 1058-1063. [CrossRef]

87. Buniyamin, N.; Ngah, W.W.; Sariff, N.; Mohamad, Z. A simple local path planning algorithm for autonomous mobile robots. Int. J. Syst. Appl. Eng. Dev. 2011, 5, 151-159.

88. Xu, Q.L.; Yu, T.; Bai, J. The mobile robot path planning with motion constraints based on Bug algorithm. In Proceedings of the 2017 Chinese Automation Congress (CAC), Jinan, China, 20-22 October 2017; pp. 2348-2352.

89. Fiorini, P.; Shiller, Z. Motion planning in dynamic environments using velocity obstacles. Int. J. Robot. Res. 1998, 17, 760-772. [CrossRef]

90. Kuwata, Y.; Wolf, M.T.; Zarzhitsky, D.; Huntsberger, T.L. Safe maritime autonomous navigation with COLREGS, using velocity obstacles. IEEE J. Ocean. Eng. 2013, 39, 110-119. [CrossRef]

91. Chen, P.; Huang, Y.; Papadimitriou, E.; Mou, J.; van Gelder, P. Global path planning for autonomous ship: A hybrid approach of Fast Marching Square and velocity obstacles methods. Ocean Eng. 2020, 214, 107793. [CrossRef]

92. Wilkie, D.; Van Den Berg, J.; Manocha, D. Generalized velocity obstacles. In Proceedings of the 2009 IEEE/RSJ International Conference on Intelligent Robots and Systems, St. Louis, MO, USA, 10-15 October 2009; pp. 5573-5578.

93. Chakravarthy, A.; Ghose, D. Obstacle avoidance in a dynamic environment: A collision cone approach. IEEE Trans. Syst. Man Cybern. Part A Syst. Hum. 1998, 28, 562-574. [CrossRef]

94. Qu, Z.; Wang, J.; Plaisted, C.E. A new analytical solution to mobile robot trajectory generation in the presence of moving obstacles. IEEE Trans. Robot. 2004, 20, 978-993. [CrossRef]

95. Fox, D.; Burgard, W.; Thrun, S. The dynamic window approach to collision avoidance. IEEE Robot. Autom. Mag. 1997, 4, 23-33. [CrossRef]

96. Brock, O.; Khatib, O. High-speed navigation using the global dynamic window approach. In Proceedings of the 1999 IEEE International Conference on Robotics and Automation (Cat. No. 99CH36288C), Detroit, MI, USA, 10-15 May 1999; Volume 1, pp. 341-346.

97. Feng, D.; Deng, L.; Sun, T.; Liu, H.; Zhang, H.; Zhao, Y. Local Path Planning Based on an Improved Dynamic Window Approach in ROS. In Proceedings of the International Conference on Computer Engineering and Networks, Xi'an, China, 16-18 October 2020; pp. 1164-1171.

98. Henkel, C.; Bubeck, A.; Xu, W. Energy efficient dynamic window approach for local path planning in mobile service robotics. IFAC-PapersOnLine 2016, 49, 32-37. [CrossRef]

99. Xie, L.; Henkel, C.; Stol, K.; Xu, W. Power-minimization and energy-reduction autonomous navigation of an omnidirectional Mecanum robot via the dynamic window approach local trajectory planning. Int. J. Adv. Robot. Syst. 2018, 15, 1729881418754563. [CrossRef] 
100. Quinlan, S.; Khatib, O. Elastic bands: Connecting path planning and control. In Proceedings of the IEEE International Conference on Robotics and Automation, Atlanta, GA, USA, 2-6 May 1993; pp. 802-807.

101. Khatib, M.; Jaouni, H.; Chatila, R.; Laumond, J.P. Dynamic path modification for car-like nonholonomic mobile robots. In Proceedings of the International Conference on Robotics and Automation, Albuquerque, NM, USA, 20-25 April 1997; Volume 4, pp. 2920-2925.

102. Pérez, L.H.; Aguilar, M.C.M.; Sánchez, N.M.; Montesinos, A.F. Path Planning Based on Parametric Curves. Adv. Path Plan. Mob. Entities 2018, 125-143. [CrossRef]

103. Rösmann, C.; Feiten, W.; Wösch, T.; Hoffmann, F.; Bertram, T. Trajectory modification considering dynamic constraints of autonomous robots. In Proceedings of the ROBOTIK 2012: 7th German Conference on Robotics, Munich, Germany, 21-22 May 2012; pp. 1-6.

104. Mirjalili, S.; Dong, J.S. Introduction to nature-inspired algorithms. In Nature-Inspired Optimizers; Springer: Cham, Switzerland, 2020; pp. 1-5.

105. Fausto, F.; Reyna-Orta, A.; Cuevas, E.; Andrade, Á.G.; Perez-Cisneros, M. From ants to whales: Metaheuristics for all tastes. Artif. Intell. Rev. 2020, 53, 753-810. [CrossRef]

106. Tang, K.S.; Man, K.F.; Kwong, S.; He, Q. Genetic algorithms and their applications. IEEE Signal Process. Mag. 1996, $13,22-37$. [CrossRef]

107. Ram, A.; Boone, G.; Arkin, R.; Pearce, M. Using genetic algorithms to learn reactive control parameters for autonomous robotic navigation. Adapt. Behav. 1994, 2, 277-305. [CrossRef]

108. Han, W.G.; Baek, S.M.; Kuc, T.Y. Genetic algorithm based path planning and dynamic obstacle avoidance of mobile robots. In Proceedings of the 1997 IEEE International Conference on Systems, Man, and Cybernetics, Computational Cybernetics and Simulation, Orlando, FL, USA, 12-15 October 1997; Volume 3, pp. 2747-2751.

109. Tuncer, A.; Yildirim, M. Dynamic path planning of mobile robots with improved genetic algorithm. Comput. Electr. Eng. 2012, 38, 1564-1572. [CrossRef]

110. Alajlan, M.; Koubaa, A.; Chaari, I.; Bennaceur, H.; Ammar, A. Global path planning for mobile robots in large-scale grid environments using genetic algorithms. In Proceedings of the 2013 International Conference on Individual and Collective Behaviors in Robotics (ICBR), Sousse, Tunisia, 15-17 December 2013; pp. 1-8.

111. Bakdi, A.; Hentout, A.; Boutami, H.; Maoudj, A.; Hachour, O.; Bouzouia, B. Optimal path planning and execution for mobile robots using genetic algorithm and adaptive fuzzy-logic control. Robot. Auton. Syst. 2017, 89, 95-109. [CrossRef]

112. Lee, H.Y.; Shin, H.; Chae, J. Path planning for mobile agents using a genetic algorithm with a direction guided factor. Electronics 2018, 7, 212. [CrossRef]

113. Elhoseny, M.; Tharwat, A.; Hassanien, A.E. Bezier curve based path planning in a dynamic field using modified genetic algorithm. J. Comput. Sci. 2018, 25, 339-350. [CrossRef]

114. Lamini, C.; Benhlima, S.; Elbekri, A. Genetic algorithm based approach for autonomous mobile robot path planning. Procedia Comput. Sci. 2018, 127, 180-189. [CrossRef]

115. Zhang, Y.; Gong, D.W.; Zhang, J.H. Robot path planning in uncertain environment using multi-objective particle swarm optimization. Neurocomputing 2013, 103, 172-185. [CrossRef]

116. Lu, L.; Gong, D. Robot path planning in unknown environments using particle swarm optimization. In Proceedings of the 2008 Fourth International Conference on Natural Computation, Washington, DC, USA, 18-20 October 2008; Volume 4, pp. $422-426$.

117. Mac, T.T.; Copot, C.; Tran, D.T.; De Keyser, R. A hierarchical global path planning approach for mobile robots based on multi-objective particle swarm optimization. Appl. Soft Comput. 2017, 59, 68-76. [CrossRef]

118. Cong, Y.Z.; Ponnambalam, S. Mobile robot path planning using ant colony optimization. In Proceedings of the 2009 IEEE/ASME International Conference on Advanced Intelligent Mechatronics, Singapore, 14-17 July 2009; pp. 851-856.

119. Cao, J. Robot global path planning based on an improved ant colony algorithm. J. Comput. Commun. 2016, 4, 63419. [CrossRef]

120. Wen, Z.Q.; Cai, Z.X. Global path planning approach based on ant colony optimization algorithm. J. Cent. South Univ. Technol. 2006, 13, 707-712. [CrossRef]

121. You, X.; Liu, K.; Liu, S. A chaotic ant colony system for path planning of mobile robot. Int. J. Hybrid Inf. Technol. 2016, 9, 329-338. [CrossRef]

122. Che, H.; Wu, Z.; Kang, R.; Yun, C. Global path planning for explosion-proof robot based on improved ant colony optimization. In Proceedings of the 2016 Asia-Pacific Conference on Intelligent Robot Systems (ACIRS), Tokyo, Japan, 20-22 July 2016 ; pp. 36-40.

123. Luo, Q.; Wang, H.; Zheng, Y.; He, J. Research on path planning of mobile robot based on improved ant colony algorithm. Neural Comput. Appl. 2020, 32, 1555-1566. [CrossRef]

124. Wang, L.; Kan, J.; Guo, J.; Wang, C. 3D path planning for the ground robot with improved ant colony optimization. Sensors 2019, 19, 815. [CrossRef]

125. Sangeetha, V.; Krishankumar, R.; Ravichandran, K.; Kar, S. Energy-efficient green ant colony optimization for path planning in dynamic 3D environments. Soft Comput. 2021, 25, 4749-4769. [CrossRef]

126. Sangeetha, V.; Krishankumar, R.; Ravichandran, K.S.; Cavallaro, F.; Kar, S.; Pamucar, D.; Mardani, A. A Fuzzy Gain-Based Dynamic Ant Colony Optimization for Path Planning in Dynamic Environments. Symmetry 2021, 13, 280. [CrossRef]

127. Saraswathi, M.; Murali, G.B.; Deepak, B. Optimal path planning of mobile robot using hybrid cuckoo search-bat algorithm. Procedia Comput. Sci. 2018, 133, 510-517. [CrossRef] 
128. Tharwat, A.; Elhoseny, M.; Hassanien, A.E.; Gabel, T.; Kumar, A. Intelligent Bézier curve-based path planning model using Chaotic Particle Swarm Optimization algorithm. Clust. Comput. 2019, 22, 4745-4766. [CrossRef]

129. Patle, B.; Pandey, A.; Jagadeesh, A.; Parhi, D.R. Path planning in uncertain environment by using firefly algorithm. Def. Technol. 2018, 14, 691-701. [CrossRef]

130. Muthukumaran, S.; Sivaramakrishnan, R. Optimal path planning for an autonomous mobile robot using dragonfly algorithm. Int J. Simul. Model. 2019, 18, 397-407. [CrossRef]

131. Elmi, Z.; Efe, M.Ö. Multi-objective grasshopper optimization algorithm for robot path planning in static environments. In Proceedings of the 2018 IEEE International Conference on Industrial Technology (ICIT), Lyon, France, 20-22 February 2018; pp. 244-249.

132. Elmi, Z.; Efe, M.Ö. Online path planning of mobile robot using grasshopper algorithm in a dynamic and unknown environment. J. Exp. Theor. Artif. Intell. 2020, 33, 467-485. [CrossRef]

133. Tsai, P.W.; Dao, T.K. Robot path planning optimization based on multiobjective grey wolf optimizer. In Proceedings of the International Conference on Genetic and Evolutionary Computing, Fuzhou, China, 7-9 November 2016; pp. $166-173$.

134. Doğan, L.; Yüzgeç, U. Robot Path Planning using Gray Wolf Optimizer. In Proceedings of the International Conference on Advanced Technologies, Computer Engineering and Science (ICATCES'18), Safranbolu, Turkey, 11-13 May 2018 ; pp. 69-74.

135. Mirjalili, S.; Lewis, A. The whale optimization algorithm. Adv. Eng. Softw. 2016, 95, 51-67. [CrossRef]

136. Dao, T.K.; Pan, T.S.; Pan, J.S. A multi-objective optimal mobile robot path planning based on whale optimization algorithm. In Proceedings of the 2016 IEEE 13th International Conference on Signal Processing (ICSP), Chengdu, China, 6-10 November 2016; pp. 337-342.

137. Mohanty, P.K.; Parhi, D.R. Cuckoo search algorithm for the mobile robot navigation. In Proceedings of the International Conference on Swarm, Evolutionary, and Memetic Computing, Chennai, India, 19-21 December 2013; pp. 527-536.

138. Ghosh, S.; Panigrahi, P.K.; Parhi, D.R. Analysis of FPA and BA meta-heuristic controllers for optimal path planning of mobile robot in cluttered environment. IET Sci. Meas. Technol. 2017, 11, 817-828. [CrossRef]

139. Hossain, M.A.; Ferdous, I. Autonomous robot path planning in dynamic environment using a new optimization technique inspired by bacterial foraging technique. Robot. Auton. Syst. 2015, 64, 137-141. [CrossRef]

140. Seraji, H.; Howard, A. Behavior-based robot navigation on challenging terrain: A fuzzy logic approach. IEEE Trans. Robot. Autom. 2002, 18, 308-321. [CrossRef]

141. Zavlangas, P.G.; Tzafestas, S.G. Motion control for mobile robot obstacle avoidance and navigation: A fuzzy logic-based approach. Syst. Anal. Model. Simul. 2003, 43, 1625-1637. [CrossRef]

142. Wang, M. Fuzzy logic based robot path planning in unknown environment. In Proceedings of the 2005 International Conference on Machine Learning and Cybernetics, Guangzhou, China, 18-21 August 2005; Volume 2, pp. 813-818.

143. Pandey, A.; Sonkar, R.K.; Pandey, K.K.; Parhi, D. Path planning navigation of mobile robot with obstacles avoidance using fuzzy logic controller. In Proceedings of the 2014 IEEE 8th International Conference on Intelligent Systems and Control (ISCO), Coimbatore, India, 10-11 January 2014; pp. 39-41.

144. Yan, Y.; Li, Y. Mobile robot autonomous path planning based on fuzzy logic and filter smoothing in dynamic environment. In Proceedings of the 2016 12th World Congress on Intelligent Control and Automation (WCICA), Guilin, China, 12-15 June 2016; pp. 1479-1484.

145. Pandey, A.; Parhi, D.R. Optimum path planning of mobile robot in unknown static and dynamic environments using Fuzzy-Wind Driven Optimization algorithm. Def. Technol. 2017, 13, 47-58. [CrossRef]

146. Zou, A.M.; Hou, Z.G.; Fu, S.Y.; Tan, M. Neural networks for mobile robot navigation: A survey. In Proceedings of the International Symposium on Neural Networks, Chengdu, China, 28 May-1 June 2006; pp. 1218-1226.

147. Engedy, I.; Horváth, G. Artificial neural network based local motion planning of a wheeled mobile robot. In Proceedings of the 2010 11th International Symposium on Computational Intelligence and Informatics (CINTI), Budapest, Hungary, 18-20 November 2010; pp. 213-218.

148. Zhang, Y.; Li, S.; Guo, H. A type of biased consensus-based distributed neural network for path planning. Nonlinear Dyn. 2017, 89, 1803-1815. [CrossRef]

149. Noguchi, N.; Terao, H. Path planning of an agricultural mobile robot by neural network and genetic algorithm. Comput. Electron. Agric. 1997, 18, 187-204. [CrossRef]

150. Xin, D.; Hua-hua, C.; Wei-kang, G. Neural network and genetic algorithm based global path planning in a static environment. J. Zhejiang Univ.-Sci. A 2005, 6, 549-554. [CrossRef]

151. Zhu, A.; Yang, S.X. An adaptive neuro-fuzzy controller for robot navigation. In Recent Advances in Intelligent Control Systems; Springer: London, UK, 2009; pp. 277-307.

152. Shi, W.; Wang, K.; Yang, S.X. A fuzzy-neural network approach to multisensor integration for obstacle avoidance of a mobile robot. Intell. Autom. Soft Comput. 2009, 15, 289-301. [CrossRef]

153. Joshi, M.M.; Zaveri, M.A. Reactive navigation of autonomous mobile robot using neuro-fuzzy system. Int. J. Robot. Autom. (IJRA) 2011, 2, 128.

154. Wang, H.; Duan, J.; Wang, M.; Zhao, J.; Dong, Z. Research on robot path planning based on fuzzy neural network algorithm. In Proceedings of the 2018 IEEE 3rd Advanced Information Technology, Electronic and Automation Control Conference (IAEAC), Chongqing, China, 12-14 October 2018; pp. 1800-1803. 
155. Mohanty, P.K.; Parhi, D.R. A new intelligent motion planning for mobile robot navigation using multiple adaptive neuro-fuzzy inference system. Appl. Math. Inf. Sci. 2014, 8, 2527-2535. [CrossRef]

156. Blum, T.; Jones, W.; Yoshida, K. PPMC training algorithm: A deep learning based path planner and motion controller. In Proceedings of the 2020 International Conference on Artificial Intelligence in Information and Communication (ICAIIC), Fukuoka, Japan, 19-21 February 2020; pp. 193-198.

157. Yu, X.; Wang, P.; Zhang, Z. Learning-Based End-to-End Path Planning for Lunar Rovers with Safety Constraints. Sensors 2021, 21, 796. [CrossRef] [PubMed]

158. Faust, A.; Oslund, K.; Ramirez, O.; Francis, A.; Tapia, L.; Fiser, M.; Davidson, J. PRM-RL: Long-range robotic navigation tasks by combining reinforcement learning and sampling-based planning. In Proceedings of the 2018 IEEE International Conference on Robotics and Automation (ICRA), Brisbane, Australia, 21-26 May 2018; pp. 5113-5120.

159. Dijkstra, E.W. A note on two problems in connexion with graphs. Numer. Math. 1959, 1, 269-271. [CrossRef]

160. Hart, P.E.; Nilsson, N.J.; Raphael, B. A formal basis for the heuristic determination of minimum cost paths. IEEE Trans. Syst. Sci. Cybern. 1968, 4, 100-107. [CrossRef]

161. Stentz, A. Optimal and efficient path planning for partially-known environments. In Proceedings of the 1994 IEEE International Conference on Robotics and Automation (ICRA), San Diego, CA, USA, 8-13 May 1994; pp. 3310-3317.

162. Stentz, A. The focussed $d^{*}$ algorithm for real-time replanning. In Proceedings of the International Joint Conference on Artificial Intelligence (IJCAI), Montreal, QC, Canada, 20-25 August 1995; Volume 95, pp. 1652-1659.

163. Koenig, S.; Likhachev, M. Incremental A*. In Proceedings of the Advances in Neural Information Processing Systems, Vancouver, BC, Canada, 9-14 December 2002; pp. 1539-1546.

164. Koenig, S.; Likhachev, M. D* Lite. In Proceedings of the AAAI/IAAI 2002, Edmonton, AB, Canada, 28 July-1 August 2002 ; Volume 15

165. Koenig, S.; Likhachev, M.; Furcy, D. Lifelong planning A*. Artif. Intell. 2004, 155, 93-146. [CrossRef]

166. Colas, F.; Mahesh, S.; Pomerleau, F.; Liu, M.; Siegwart, R. $3 \mathrm{~d}$ path planning and execution for search and rescue ground robots. In Proceedings of the 2013 IEEE/RSJ International Conference on Intelligent Robots and Systems, Tokyo, Japan, 3-7 November 2013; pp. 722-727.

167. Likhachev, M.; Ferguson, D.; Gordon, G.; Stentz, A.; Thrun, S. Anytime search in dynamic graphs. Artif. Intell. 2008, 172, 1613-1643. [CrossRef]

168. Dolgov, D.; Thrun, S.; Montemerlo, M.; Diebel, J. Path planning for autonomous vehicles in unknown semi-structured environments. Int. J. Robot. Res. 2010, 29, 485-501. [CrossRef]

169. Ferguson, D.; Stentz, A. The Field D* Algorithm for Improved Path Planning and Replanning in Uniform and Non-Uniform Cost Environments; Technical Report CMU-RI-TR-05-19; Robotics Institute, Carnegie Mellon University: Pittsburgh, PA, USA, 2005.

170. Carsten, J.; Rankin, A.; Ferguson, D.; Stentz, A. Global planning on the Mars Exploration Rovers: Software integration and surface testing. J. Field Robot. 2009, 26, 337-357. [CrossRef]

171. Nash, A.; Daniel, K.; Koenig, S.; Felner, A. Theta*: Any-angle path planning on grids. In Proceedings of the AAAI Conference on Artificial Intelligence, Vancouver, BC, Canada, 22-26 July 2007; Volume 7, pp. 1177-1183.

172. Daniel, K.; Nash, A.; Koenig, S.; Felner, A. Theta*: Any-angle path planning on grids. J. Artif. Intell. Res. 2010, 39, 533-579. [CrossRef]

173. Nash, A.; Koenig, S.; Likhachev, M. Incremental Phi*: Incremental any-angle path planning on grids. In Proceedings of the Twenty-First International Joint Conference on Artificial Intelligence, Pasadena, CA, USA, 12-17 July 2009; pp. 1-7.

174. Nash, A.; Koenig, S.; Tovey, C. Lazy Theta*: Any-angle path planning and path length analysis in 3D. In Proceedings of the Twenty-Fourth AAAI Conference on Artificial Intelligence, Atlanta, GA, USA, 11-15 July 2010; pp. 147-154.

175. Choi, S.; Yu, W. Any-angle path planning on non-uniform costmaps. In Proceedings of the 2011 IEEE International Conference on Robotics and Automation (ICRA), Shanghai, China, 9-13 May 2011; pp. 5615-5621.

176. Šišlák, D.; Volf, P.; Pechoucek, M. Accelerated A* trajectory planning: Grid-based path planning comparison. In Proceedings of the 19th International Conference on Automated Planning \& Scheduling (ICAPS), Thessaloniki, Greece, 19-23 September 2009; pp. 74-81.

177. Yap, P.; Burch, N.; Holte, R.C.; Schaeffer, J. Block A*: Database-driven search with applications in any-angle path-planning. In Proceedings of the Twenty-Fifth AAAI Conference on Artificial Intelligence, San Francisco, CA, USA, 7-11 August 2011; pp. 120-125.

178. Yap, P.K.Y.; Burch, N.; Holte, R.C.; Schaeffer, J. Any-angle path planning for computer games. In Proceedings of the Seventh Artificial Intelligence and Interactive Digital Entertainment Conference, Palo Alto, CA, USA, 11-14 August 2011 ; pp. $201-207$.

179. Muñoz, P.; R-Moreno, M.D. S-Theta: Low steering path-planning algorithm. In Research and Development in Intelligent Systems XXIX; Springer: London, UK, 2012; pp. 109-121.

180. Muñoz, P.; R-Moreno, M.D.; Castaño, B. 3Dana: Path Planning on 3D Surfaces. In Proceedings of the Thirty-Sixth SGAI International Conference on Innovative Techniques and Applications of Artificial Intelligence, Cambridge, UK, 13-15 December 2016; pp. 177-191.

181. Muñoz, P.; R-Moreno, M.D.; Castaño, B. 3Dana: A path planning algorithm for surface robotics. Eng. Appl. Artif. Intell. 2017, 60, 175-192. [CrossRef] 
182. Uras, T.; Koenig, S. Speeding-up any-angle path-planning on grids. In Proceedings of the Twenty-Fifth International Conference on Automated Planning and Scheduling, Jerusalem, Israel, 7-11 June 2015; pp. 234-238.

183. Uras, T.; Koenig, S. An empirical comparison of any-angle path-planning algorithms. In Proceedings of the Eighth Annual Symposium on Combinatorial Search, Ein Gedi, the Dead Sea, Israel, 11-13 June 2015; pp. 206-210.

184. Harabor, D.D.; Grastien, A. An optimal any-angle pathfinding algorithm. In Proceedings of the Twenty-Third International Conference on Automated Planning and Scheduling, Rome, Italy, 10-14 June 2013; pp. 308-311.

185. Harabor, D.D.; Grastien, A.; Öz, D.; Aksakalli, V. Optimal any-angle pathfinding in practice. J. Artif. Intell. Res. 2016, 56, 89-118. [CrossRef]

186. Karaman, S.; Frazzoli, E. Sampling-based algorithms for optimal motion planning. Int. J. Robot. Res. 2011, 30, 846-894. [CrossRef]

187. LaValle, S.M. Planning Algorithms; Cambridge University Press: New York, NY, USA, 2006.

188. Kuffner, J.J.; LaValle, S.M. RRT-connect: An efficient approach to single-query path planning. In Proceedings of the 2000 ICRA, Millennium Conference, IEEE International Conference on Robotics and Automation, Symposia Proceedings (Cat. No. 00CH37065), San Francisco, CA, USA, 24-28 April 2000; Volume 2, pp. 995-1001.

189. Yershova, A.; Jaillet, L.; Siméon, T.; LaValle, S.M. Dynamic-domain RRTs: Efficient exploration by controlling the sampling domain. In Proceedings of the 2005 IEEE International Conference on Robotics and Automation (ICRA), Barcelona, Spain, 18-22 April 2005; pp. 3856-3861.

190. Arslan, O.; Tsiotras, P. Use of relaxation methods in sampling-based algorithms for optimal motion planning. In Proceedings of the 2013 IEEE International Conference on Robotics and Automation (ICRA), Karlsruhe, Germany, 6-10 May 2013; pp. 2421-2428.

191. Gammell, J.D.; Srinivasa, S.S.; Barfoot, T.D. Informed RRT*: Optimal sampling-based path planning focused via direct sampling of an admissible ellipsoidal heuristic. In Proceedings of the 2014 IEEE/RSJ International Conference on Intelligent Robots and Systems, Chicago, IL, USA, 14-18 September 2014; pp. 2997-3004.

192. Gammell, J.D.; Srinivasa, S.S.; Barfoot, T.D. Batch informed trees (BIT*): Sampling-based optimal planning via the heuristically guided search of implicit random geometric graphs. In Proceedings of the 2015 IEEE International Conference on Robotics and Automation (ICRA), Seattle, WA, USA, 25-30 May 2015; pp. 3067-3074.

193. Choudhury, S.; Gammell, J.D.; Barfoot, T.D.; Srinivasa, S.S.; Scherer, S. Regionally accelerated batch informed trees (rabit*): A framework to integrate local information into optimal path planning. In Proceedings of the 2016 IEEE International Conference on Robotics and Automation (ICRA), Stockholm, Sweden, 16-20 May 2016; pp. 4207-4214.

194. Strub, M.P.; Gammell, J.D. Adaptively Informed Trees (AIT*): Fast asymptotically optimal path planning through adaptive heuristics. In Proceedings of the 2020 IEEE International Conference on Robotics and Automation (ICRA), Virtual, 31 May-31 August 2020; pp. 3191-3198.

195. Strub, M.P.; Gammell, J.D. Advanced BIT*(ABIT*): Sampling-based planning with advanced graph-search techniques. In Proceedings of the 2020 IEEE International Conference on Robotics and Automation (ICRA), Virtual, 31 May-31 August 2020; pp. 130-136.

196. Kavraki, L.E.; Svestka, P.; Latombe, J.C.; Overmars, M.H. Probabilistic roadmaps for path planning in high-dimensional configuration spaces. IEEE Trans. Robot. Autom. 1996, 12, 566-580. [CrossRef]

197. Park, B.; Choi, J.; Chung, W.K. Incremental hierarchical roadmap construction for efficient path planning. ETRI J. 2018, 40, 458-470. [CrossRef]

198. Ichter, B.; Schmerling, E.; Lee, T.W.E.; Faust, A. Learned critical probabilistic roadmaps for robotic motion planning. In Proceedings of the 2020 IEEE International Conference on Robotics and Automation (ICRA), Virtual, 31 May-31 August 2020; pp. 9535-9541.

199. Ichter, B.; Schmerling, E.; Pavone, M. Group Marching Tree: Sampling-based approximately optimal motion planning on GPUs. In Proceedings of the 2017 First IEEE International Conference on Robotic Computing (IRC), Taichung, Taiwan, 10-12 April 2017; pp. 219-226.

200. Dunlap, D.D.; Caldwell, C.V.; Collins, E.G. Nonlinear model predictive control using sampling and goal-directed optimization. In Proceedings of the 2010 IEEE International Conference on Control Applications, Yokohama, Japan, 8-10 September 2010; pp. 1349-1356.

201. Wang, L.L.; Pan, L.X. Research on SBMPC Algorithm for Path Planning of Rescue and Detection Robot. Discret. Dyn. Nat. Soc. 2020, 2020, 7821942. [CrossRef]

202. Tonon, D.; Aronna, M.S.; Kalise, D. Optimal Control: Novel Directions and Applications; Springer: Cham, Switzerland, 2017 ; Volume 1.

203. Bellman, R. Dynamic programming. Science 1966, 153, 34-37. [CrossRef] [PubMed]

204. Festa, A.; Guglielmi, R.; Hermosilla, C.; Picarelli, A.; Sahu, S.; Sassi, A.; Silva, F.J. Hamilton-Jacobi-Bellman Equations. In Optimal Control: Novel Directions and Applications; Springer International Publishing: Cham, Switzerland, 2017; pp. $127-261$.

205. Sethian, J.A. Level Set Methods and Fast Marching Methods: Evolving Interfaces in Computational Geometry, Fluid Mechanics, Computer Vision, and Materials Science; Cambridge University Press: Cambridge, UK, 1999; Volume 3.

206. Chiang, C.H.; Chiang, P.J.; Fei, J.C.C.; Liu, J.S. A comparative study of implementing Fast Marching Method and A* SEARCH for mobile robot path planning in grid environment: Effect of map resolution. In Proceedings of the 2007 IEEE Workshop on Advanced Robotics and Its Social Impacts, Hsinchu, Taiwan, 9-11 December 2007; pp. 1-6.

207. Kimmel, R.; Sethian, J.A. Optimal algorithm for shape from shading and path planning. J. Math. Imaging Vis. 2001, 14, 237-244. [CrossRef] 
208. Garrido, S.; Malfaz, M.; Blanco, D. Application of the fast marching method for outdoor motion planning in robotics. Robot. Auton. Syst. 2013, 61, 106-114. [CrossRef]

209. Garrido, S.; Álvarez, D.; Moreno, L. Path Planning for Mars Rovers Using the Fast Marching Method. In Proceedings of the Robot 2015: Second Iberian Robotics Conference, Lisbon, Portugal, 19-21 November 2015; pp. 93-105.

210. Liu, Y.; Liu, W.; Song, R.; Bucknall, R. Predictive navigation of unmanned surface vehicles in a dynamic maritime environment when using the fast marching method. Int. J. Adapt. Control Signal Process. 2017, 31, 464-488. [CrossRef]

211. Liu, Y.; Bucknall, R. The angle guidance path planning algorithms for unmanned surface vehicle formations by using the fast marching method. Appl. Ocean Res. 2016, 59, 327-344. [CrossRef]

212. Philippsen, R. E* Interpolated Graph Replanner. In Proceedings of the Workshop Proceedings on Algorithmic Motion Planning for Autonomous Robots in Challenging Environments, Held in Conjunction with the IEEE International Conference on Intelligent Robots and Systems (IROS), San Diego, CA, USA, 29 October-2 November 2007; Volume 69.

213. Philippsen, R.; Kolski, S.; Macek, K.; Jensen, B. Mobile robot planning in dynamic environments and on growable costmaps. In Proceedings of the 2008 IEEE International Conference on Robotics and Automation (ICRA), Pasadena, CA, USA, 19-23 May 2008; pp. 1-8.

214. Xu, B.; Stilwell, D.J.; Kurdila, A.J. Fast path re-planning based on fast marching and level sets. J. Intell. Robot. Syst. 2013, 71, 303-317. [CrossRef]

215. Sethian, J.A.; Vladimirsky, A. Ordered upwind methods for static Hamilton-Jacobi equations: Theory and algorithms. SIAM J. Numer. Anal. 2003, 41, 325-363. [CrossRef]

216. Xu, J.; Chen, Y.; Yang, X.; Zhang, M. Fast Marching Based Path Generating Algorithm in Anisotropic Environment with Perturbations. IEEE Access 2019, 8, 5256-5263. [CrossRef]

217. Shum, A.; Morris, K.; Khajepour, A. Convergence rate for the ordered upwind method. J. Sci. Comput. 2016, 68, 889-913. [CrossRef]

218. Kao, C.Y.; Osher, S.; Tsai, Y.H. Fast sweeping methods for static Hamilton-Jacobi equations. SIAM J. Numer. Anal. 2005, 42, 2612-2632. [CrossRef]

219. Bak, S.; McLaughlin, J.; Renzi, D. Some improvements for the fast sweeping method. SIAM J. Sci. Comput. 2010, 32, $2853-2874$. [CrossRef]

220. Detrixhe, M.; Gibou, F.; Min, C. A parallel fast sweeping method for the Eikonal equation. J. Comput. Phys. 2013, $237,46-55$. [CrossRef]

221. Jeong, W.K.; Whitaker, R.T. A fast iterative method for eikonal equations. SIAM J. Sci. Comput. 2008, 30, 2512-2534. [CrossRef]

222. Ratliff, N.; Zucker, M.; Bagnell, J.A.; Srinivasa, S. CHOMP: Gradient optimization techniques for efficient motion planning. In Proceedings of the 2009 IEEE International Conference on Robotics and Automation (ICRA), Kobe, Japan, 12-17 May 2009; pp. 489-494.

223. Van Den Berg, J.; Patil, S.; Alterovitz, R. Motion planning under uncertainty using differential dynamic programming in belief space. In Robotics Research; Springer: Cham, Switzerland, 2017; pp. 473-490.

224. Ajanović, Z.; Stolz, M.; Horn, M. Energy-efficient driving in dynamic environment: Globally optimal MPC-like motion planning framework. In Advanced Microsystems for Automotive Applications 2017; Springer: Cham, Switzerland, 2018; pp. 111-122.

225. Kalmár-Nagy, T.; D’Andrea, R.; Ganguly, P. Near-optimal dynamic trajectory generation and control of an omnidirectional vehicle. Robot. Auton. Syst. 2004, 46, 47-64. [CrossRef]

226. Ma, C.S.; Miller, R.H. MILP optimal path planning for real-time applications. In Proceedings of the 2006 American Control Conference, Minneapolis, MN, USA, 14-16 June 2006; p. 6.

227. Kogan, D.; Murray, R. Optimization-based navigation for the DARPA Grand Challenge. In Proceedings of the 45th Conference on Decision and Control (CDC), San Diego, CA , USA, 13-15 December 2006; p. 6. 